\title{
Volatile Compounds of Endophytic Bacillus spp. have Biocontrol Activity Against Sclerotinia sclerotiorum
}

\author{
Venance Colman Massawe, Alvina Hanif, Ayaz Farzand, David Kibe Mburu, Sylvans Ochieng Ochola, \\ Liming Wu, Hafiz Abdul Samad Tahir, Qin Gu, Huijun Wu, and Xuewen Gao ${ }^{\dagger}$
}

Department of Plant Pathology, College of Plant Protection, Nanjing Agricultural University, Key Laboratory of Integrated Management of Crop Diseases and Pests, Ministry of Education, Nanjing, PR China.

Accepted for publication 18 June 2018.

\begin{abstract}
To develop an effective biological agent to control Sclerotinia sclerotiorum, three endophytic Bacillus spp. strains with high antagonistic activity were isolated from maize seed and characterized. In vitro assays revealed that the Bacillus endophytes could produce volatile organic compounds (VOC) that reduced sclerotial production and inhibited mycelial growth of S. sclerotiorum. Gas chromatography-mass spectrometry revealed that the selected strains produced 16 detectable VOC. Eight of the produced VOC exhibited negative effects on S. sclerotiorum, while a further four induced accumulation of reactive oxygen species in mycelial cells. A mixture of VOC produced by Bacillus velezensis VM11 caused morphological changes in the ultrastructure and organelle membranes of

S. sclerotiorum mycelial cells. The bromophenol blue assay revealed a yellow color of untreated fungal mycelium, which grew faster and deeper from 24 to $72 \mathrm{~h}$ postinoculation, as an indication of reduced $\mathrm{pH}$. The potassium permanganate $\left(\mathrm{KMnO}_{4}\right)$ titration assay showed that the rate of oxalic acid accumulation was higher in minimal salt liquid medium cultures inoculated with untreated fungal plugs compared with the Bacillus VOC-treated ones. Interestingly, biological control assays using host-plant leaves challenged with treated fungal mycelial plugs produced reduced lesions compared with the control. These findings provide new viable possibilities of controlling diseases caused by S. sclerotiorum using VOC produced by Bacillus endophytes.
\end{abstract}

The ascomycete Sclerotinia sclerotiorum (Lib.) de Bary is a welldocumented necrotrophic plant pathogen, which causes serious economic losses to crops around the world, especially to the broadleaved crops (Boland and Hall 1987, 1994). Mycelial growth and sclerotia production have been documented as pathogenicity factors of this fungus (Bloomfield and Alexander 1967). However, the oxalic acid (OA) produced by this pathogen is known to be a primary determinant of its pathogenicity to the host-plant tissues (Bolton et al. 2006; Seifbarghi et al. 2017). After successful colonization of its host plant, this fungus secretes several cell-wall-degrading enzymes (CWDE) into the plant tissues, which directly digest host cell walls (Purdy 1979). The polygalacturonases produced by this fungus, which are the typical pectinolytic CWDE, have been elucidated to be its main virulence contributors (Bolton et al. 2006). Other nonpectinolytic enzymes such as cellulases and proteases have also been documented as contributors to virulence in host plants (Seifbarghi et al. 2017).

The abovementioned CWDE of $S$. sclerotiorum are functionally triggered by a low-pH environment (pH 3.0 to 4.5) (Kim et al. 2008; Liang et al. 2015). To create such acidic environments, this fungus can produce OA during the early stage of host-pathogen interaction, which aids in manipulation of host defense pathways to avoid recognition during the invasion (Kim et al. 2008; Liang et al. 2015; Williams et al. 2011). Moreover, OA produced by S. sclerotiorum has been reported to induce plant cell death, in favor of its necrotrophic virulence characteristics (Liang et al. 2015; Williams et al. 2011). A recent report by Liang et al. (2015) showed that an

†Corresponding author: Xuewen Gao; E-mail: gaoxw@njau.edu.cn

Funding: This work was supported by the National Key Research and Development Program of China (grant number 2017YFD0200400), the National Natural Science Foundation of China (grant number 31471811), and the Key research and development plan of Jiangsu Province (grant number BE2015354).

(c) 2018 The American Phytopathological Society
OA-deficient mutant of $S$. sclerotiorum resulted in impaired virulence against susceptible host plants, because the host plants could recognize the fungal pathogen and subsequently respond by unleashing countermeasures, including an oxidative burst coupled with callose deposition. To ensure sustainability of its lifecycle, $S$. sclerotiorum produces sclerotia (melanized hard structure) that enable the pathogen to maintain viability in harsh environments for several years (Bloomfield and Alexander 1967). However, when the growth conditions are favorable, sclerotia germinate to form an apothecial cup which subsequently emits ascospores that are easily spread by wind, resulting in disease outbreaks (Bloomfield and Alexander 1967).

Several control strategies such as crop rotation, moisture monitoring, and breeding of resistant crops have resulted in significant failure due to the formation of sclerotia that can survive in the soil for a long time, and due to the ability of the pathogen to infect several rotational crops. The most effective control option has been application of synthetic fungicides. Nevertheless, dependence on these chemical treatments has raised serious environmental and health hazard concerns (Boland and Hall 1987). Recently, biological control has emerged and captured scientific research attention as an effective means of controlling plant pathogens, coupled with environmental preservation (Fernando et al. 2005; Minuto et al. 2006). Biological control agents, particularly Bacillus endophytes, have been reported to protect plants against phytopathogens such as fungi, bacteria, and nematodes (Berg and Hallmann 2006; Ping and Boland 2004). The biocontrol activity exhibited by these Bacillus endophytes is often due to the production of complex sets of volatile organic compounds (VOC), which can protect plants directly against phytopathogens or indirectly through induction of plant resistance (Kai et al. 2009; Sumayo et al. 2013; Tahir et al. 2017; Zamioudis et al. 2015). This ability of bacteria to produce low molecular weight compounds that have direct or indirect effects on other organisms and microorganisms was discovered a few decades back (McCain 1966). These compounds have been classified into clusters of esters, alkanes, alkenes, alkynes, alcohols, terpenoids, 
aldehydes, ketones, and sulfur-containing compounds (Mitchell et al. 2010; Wan et al. 2008). Among these compounds, nonanal, 2-undecanone, cyclohexanol, $n$-decanal, benzothiazole, 2-ethyl-1hexanol, pyrazine (2,5-dimethyl), and dimethyl trisulfide have been reported to possess biocontrol activity (Tahir et al. 2017; Xie et al. 2018).

This study highlights the effects of VOC produced by Bacillus endophytes against the plant pathogen $S$. sclerotiorum. We report that Bacillus endophytes produced VOC that had adverse effects on growth of fungal mycelia and sclerotia production and that reduced levels of OA production in S. sclerotiorum. An understanding of how the VOC of Bacillus endophytes alter this pathogen may enable us to exploit $S$. sclerotiorum's weaknesses to our benefit, thus resulting in a breakthrough in controlling the diseases caused by this fungal pathogen.

\section{MATERIALS AND METHODS}

Strains culture growth and seed procurement. The ascomycete fungus $S$. sclerotiorum strain 1980 was obtained from the Institute of Biotechnology, College of Agriculture and Biotechnology, Zhejiang University, Hangzhou, China. The fungus was grown on potato dextrose agar (PDA) for 3 days at $25^{\circ} \mathrm{C}$ and maintained at $4{ }^{\circ} \mathrm{C}$ for future use. The local maize variety UYOLE 629, which grows optimally in the highland areas of Tanzania, was obtained from a farmer at Makete District, Njombe, Tanzania. The seed were selected based on health, with no signs of cracking or distortion.

Bacterial isolation. Bacillus endophytes were isolated from maize seed following the procedure described by Rijavec et al. (2007). Briefly, the maize seed were washed in sterile water, dipped in $10 \%$ sodium hypochlorite $(\mathrm{NaClO})$ solution for $5 \mathrm{~min}$, and immersed in $70 \%$ ethanol for $3 \mathrm{~min}$, followed by rinsing three times in sterile water. The surface-sterilized seed were aseptically blended into $70 \mathrm{ml}$ of half-strength nutrient broth (NB) and incubated at $28^{\circ} \mathrm{C}$ for $4 \mathrm{~h}$ in a rotary shaker (IS-RDV1; CRYSTAL) $(110 \mathrm{rpm}$ ). The cultures were incubated further for $1 \mathrm{~h}$ after being amended with half-strength NB containing cycloheximide $(1: 10)$ at $200 \mathrm{ml}$ liter $^{-1}$. The resultant mixture $(5 \mu \mathrm{l})$ was streaked on R2A medium plates (Rijavec et al. 2007) and incubated at $28^{\circ} \mathrm{C}$ for $48 \mathrm{~h}$. Forty bacterial colonies were transferred onto Luria-Bertani (LB) plates to obtain pure cultures. Single colonies were picked into $20 \mathrm{ml}$ of LB broth and agitated in rotary shaker (IS-RDV1; CRYSTAL) for $24 \mathrm{~h}$ at $28^{\circ} \mathrm{C}$. The subsequent bacterial strains were maintained at $-20^{\circ} \mathrm{C}$ (DW-25L262; Haier Biomedical) as saturated cultures containing $20 \%$ glycerol (wt/vol).

Antibiotic activity of secondary metabolites produced by Bacillus endophytes. The antibiotic activities of the five bacterial endophyte isolates VM10, VM21, VM11, VM1, and VM42, were tested against the pathogen $S$. sclerotiorum by dual-culture plate technique (Zhao et al. 2014). Discs of S. sclerotiorum hyphae (6 ml in diameter) were cut from the plate margin using a sterilized cock borer and aseptically cultured at the center of PDA Petri plates. Aliquots $(2 \mu \mathrm{l})$ of Bacillus endophyte cultures incubated overnight in LB broth were inoculated in duplicate, $3 \mathrm{~cm}$ away from pathogen inoculum. In control plates, $2 \mu \mathrm{l}$ of sterile water were used instead of Bacillus cultures. Each treatment was applied to three replicate plates and was repeated at least three times. Plates were incubated at $25^{\circ} \mathrm{C}$ in an incubator and the inhibition zones were measured from the edge of Bacillus colonies to the end of fungal mycelial growth after 5 days of incubation. Bacillus endophytes that exhibited strong antibiotic activity against $S$. sclerotiorum in the dual-culture assay were selected for identification and further tested for their ability to produce VOC with antifungal activity.

Molecular identification of endophytic bacteria. Three Bacillus endophytes (VM10, VM11, and VM42) that antagonized the fungal pathogen in dual-culture assay, among five bacterial isolates randomly picked from preserved bacterial strains, were identified based on 16S ribosomal RNA (rRNA) and gyrase subunit
A (gyrA) genes. The primers 27F ( $5^{\prime}$ AGAGTTTGATCMTGGCT CAG 3') and 1492R (5' GGYTACCTTGTTACGACTT 3') (Ueda et al. 2013), and gyrA-F (5' CAGTCAGGAAATGCGTACGTCCTT $\left.3^{\prime}\right)$ and gyrA-R (5' CAAGGTAATGCTCCAGGCATTGCT 3') (De Clerck et al. 2004), were used to amplify the 16S rRNA and gyrA genes, respectively. The polymerase chain reaction (PCR) tubes containing $25 \mu \mathrm{l}$ of PCR mixture with $2 \mu \mathrm{l}$ of DNA extracts, $3 \mu \mathrm{l}$ of $1 \times$ Taq reaction buffer, $2.8 \mu \mathrm{l}$ of $\mathrm{dNT}, 2.8 \mu \mathrm{l}$ of $\mathrm{MgCl}_{2}, 1 \mu \mathrm{l}$ of each primer, $0.4 \mu \mathrm{l}$ of Taq enzyme, and $12 \mu \mathrm{l}$ of double-distilled sterilized water were run in a Bio-Rad Thermal Cycler (S1000). The subsequent gel products were subjected to Sanger sequencing (Genscript Co. Ltd.). The neighbor-joining method was used to construct phylogenetic trees based on 16S rRNA and gyrA gene sequences with homologous strain sequences retrieved from GenBank, using Clustal W in MEGA 6.06 (Wu et al. 2014a; Xie et al. 2018).

Evaluation of antibiotic activity of VOC produced by Bacillus endophytes against $S$. sclerotiorum. The effects of VOC produced by the Bacillus endophytes VM10, VM11, and VM42 were tested toward S. sclerotiorum mycelial growth in centrally partitioned (bicompartment) 9-mm Petri dishes, to prevent direct contact between the assayed organisms. Three Bacillus strains that showed the highest inhibitory activity in the dual-culture assay were further assayed for their ability to produce VOC with antifungal characteristics. Overnight-incubated Bacillus endophyte cultures $(5 \mu \mathrm{l})$ were spread on one side of the partition plates containing minimal salt medium (MSM) (Tahir et al. 2017), and a 6-mmdiameter fungal mycelia plug was placed at the center-end of the other partition containing PDA medium. S. sclerotiorum plates cultured without Bacillus inoculum were treated as a control. The plates were sealed by parafilm (PM-996; PARAFILM, Bemis) and incubated at $25^{\circ} \mathrm{C}$. The radial mycelial growth of $S$. sclerotiorum was recorded 5 days postinoculation (dpi), and the inhibition rate (\%) was calculated (Gong et al. 2015). To further evaluate the effects of Bacillus endophyte VOC on S. sclerotiorum, 6-mmdiameter fungal plugs were taken from an $S$. sclerotiorum mycelial mat previously exposed to Bacillus VOC for $48 \mathrm{~h}$. The plugs were then placed at the center of PDA Petri dishes $(9 \mathrm{~mm})$, sealed, and incubated at $25^{\circ} \mathrm{C}$. The Petri dishes containing VOC-untreated fungal mycelial plugs served as a control. Growth and development of fungal mycelia were monitored for $84 \mathrm{~h}$ by recording mycelial growth (in millimeters) at intervals of $12 \mathrm{~h}$. Experiments were conducted three times, involving three replications each time.

Gas chromatography-mass spectrometry analysis. Solidphase microextraction (SPME) gas chromatography-mass spectrometry (GC-MS) analysis was conducted to identify VOC produced by the Bacillus endophytes VM10, VM11, and VM42 that suppressed fungal growth in the partition-plate assay. Bacillus endophyte cultures $(15 \mu \mathrm{l})$ with an optical density (OD) of 1.2 at $600 \mathrm{~nm}$ were grown on $40 \mathrm{ml}$ of MSM contained in 100-ml glass vials. The vials were firmly sealed by parafilm and rubber lids, then incubated at $28^{\circ} \mathrm{C}$ for 5 days before VOC collection. MSM without Bacillus inoculation was used as a control. The VOC were collected and analyzed following the description of Tahir et al. (2017). Briefly, the vials were water bathed in a heating metal block (DF-101S; Lichen) at $50^{\circ} \mathrm{C}$ with $2 \mathrm{~cm}$ of divinyl benzene/carboxy/ Polydimethylsiloxane PDMS $(50 / 30 \mu \mathrm{m})$ SPME (SUPELCO Analytical) fiber inserted into the headspace of the vial samples and incubated for $30 \mathrm{~min}$. The SPME fiber was inserted into an injection port of a GC-MS mass spectrometer, and allowed desorbing at $220^{\circ} \mathrm{C}$ for $5 \mathrm{~min}$ and running for $30 \mathrm{~min}$. The starting temperature for heating the column was $35^{\circ} \mathrm{C}$ for $3 \mathrm{~min}$, which increased to $180^{\circ} \mathrm{C}$ at $10^{\circ} \mathrm{C} \mathrm{min}^{-1}$, further advanced to $240^{\circ} \mathrm{C}$ at $4^{\circ} \mathrm{C} \mathrm{min}{ }^{-1}$, and finally was retained for $5 \mathrm{~min}$. The mass spectrometer was operated in the electron ionization mode at $70 \mathrm{eV}$ with a source temperature of $230^{\circ} \mathrm{C}$, through a continuous scan of $\mathrm{m} / \mathrm{z} 50$ to 500 . The positive detection of VOC was achieved by comparing their retention time and mass spectrum, with the available authentic standard deposited in the National Institute of Standards and Technology database. The 
VOC in treated samples that were not found in the control were considered the final Bacillus-produced VOC.

The fungistatic action of Bacillus VOC on sclerotia production, viability, and development. A bicompartment plate method was used for sclerotia assay, as previously described. The fungal mycelial plugs (6 $\mathrm{mm}$ in diameter) were cut from the edge of an actively growing fungal culture and placed on one side of plate containing PDA. Either $5 \mu$ of Bacillus endophyte cultures with an OD of 1.2 at $600 \mathrm{~nm}$ or double-distilled sterile water that served as a control was pipetted onto the other side of the plate. The plates were firmly sealed by parafilm and incubated at $25^{\circ} \mathrm{C}$, and sclerotia production was assayed after $14 \mathrm{dpi}$. As described previously, the fungal hyphae plugs initially subjected to Bacillus VOC for $48 \mathrm{~h}$ were placed at the center of PDA Petri dishes and incubated at $25^{\circ} \mathrm{C}$. Control plates contained VOC-untreated fungal hyphae plugs. The mean weight, number, and inner color of sclerotia were observed from triplicated Petri plates after $14 \mathrm{dpi}$. Moreover, healthy sclerotia were harvested from 14-day-old plates, to evaluate their germination upon culturing with Bacillus endophytes in bicompartment plates. After washing three times in sterile water and aseptically air drying, 3 sclerotia were grown in one partition of a plate in triplicate, while the other half was inoculated with $5 \mu \mathrm{l}$ of Bacillus culture followed by incubation at $25^{\circ} \mathrm{C}$ for 7 days. All experimental setups were in triplicate.

Antifungal activity of synthetic chemicals on $\mathrm{S}$. sclerotiorum. The VOC previously identified through GC-MS analysis (Table 1) were purchased as standard pure chemicals from Sigma-Aldrich for in vitro assays of their antifungal activity against $S$. sclerotiorum. Dimethyl sulfoxide (DMSO) was used as a solvent for chemical compounds that were in a solid state, to obtain a final concentration of $1 \mathrm{mg} \mathrm{ml}-1$. Fungal plugs of $6 \mathrm{~mm}$ in diameter were excised from the actively growing $S$. sclerotiorum mycelia plate and fixed in one partition of bicompartment Petri dishes filled with PDA medium. Synthetic VOC $(50 \mu \mathrm{l})$ was applied to $1-\mathrm{cm}$-diameter filter papers and placed in the other half of the Petri dishes. Control plates were prepared in the same manner but the filter papers were supplemented with DMSO. The Petri dishes were then sealed with parafilm to prevent the leak of VOC. The plates were incubated at $25^{\circ} \mathrm{C}$. The rate $(\%)$ of radial mycelial growth was calculated after 5 days of incubation. The assay was performed three times in triplicate. The most effective synthetic VOC against $S$. sclerotiorum mycelial growth were selected for further antibiotic evaluation, including determination of their minimum inhibitory concentrations (MIC).

Reactive oxygen species accumulation. Fungal mycelia were treated with either Bacillus VOC or synthetic VOC to assess their impact on reactive oxygen species (ROS) induction into the fungal mycelial cells. S. sclerotiorum mycelia were cultured with $5 \mu \mathrm{l}$ of Bacillus cultures or $5 \mu \mathrm{l}$ of MIC of each pure chemical for $48 \mathrm{~h}$ in bicompartment plates. The fungal plates incubated only with MSM for Bacillus VOC assay or DMSO for synthetic VOC were treated as controls. After $48 \mathrm{~h}$, fungal mycelia were then transferred to $1.5-\mathrm{ml}$ Eppendorf tubes containing $10 \mathrm{mM}$ sodium phosphate buffer $(7.4 \mathrm{pH})$. The samples were further stained with $10 \mu \mathrm{l}$ of dichloro-dihydro-fluorescein diacetate (DCFH-DA) (JianCheng Bioengineering Institute), and incubated for $30 \mathrm{~min}$ at $25^{\circ} \mathrm{C}$ in the dark (Gu et al. 2017). Microscopic observations and analysis were performed using an Olympus IX71 microscope and Image Pro Express software.

Scanning electron microscopy and transmission electron microscopy analysis. Scanning electron microscopy (SEM) and transmission electron microscopy (TEM) analysis were used to assess the influence of VOC emitted by Bacillus velezensis VM11 on morphology and ultrastructure of pathogen hyphae. Fungal mycelia were extracted from both VOC-treated and untreated Petri plates. The samples were fixed in $2 \%$ glutaraldehyde (Solarbio, Co. Ltd.) in $0.05 \%$ potassium phosphate buffer for $2 \mathrm{~h}$ and further postfixed at $4{ }^{\circ} \mathrm{C}$ for $2 \mathrm{~h}$ with the same buffer in $1 \%$ osmium tetroxide, tailed with dehydration through a number ethanol gradient (50 to $100 \%)(\mathrm{vol} / \mathrm{vol})$. With the help of gold staining, electron micrograph images were captured using Hitachi Science System SEM (S-3000 N; Hitachi). Mycelia samples for ultrastructural analysis were prepared following the embedding procedure described by Gu et al. (2017). Micrographs were captured using a transmission electron microscope (H-7650; Hitachi) through AMT_V700 software, version 7.0.0.184.

Virulence and pathogenicity assays on detached leaves. The ability of the VOC produced by $B$. velezensis VM11 on $S$. sclerotiorum to incite disease was assayed on leaves from three host plants (tomato, soybean, and tobacco). Fully expanded leaves

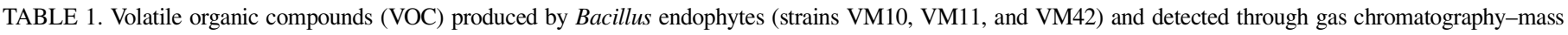
spectrometry (GC-MS) ${ }^{\mathrm{a}}$

\begin{tabular}{|c|c|c|c|c|c|c|c|c|}
\hline $\mathrm{VOC}^{\mathrm{b}}$ & Identity $(\%)^{\mathrm{c}}$ & Peak area $(\%)^{\mathrm{d}}$ & $\mathrm{RT}^{\mathrm{e}}$ & $\mathrm{MW}^{\mathrm{f}}$ & $\mathrm{MF}^{\mathrm{g}}$ & VM10 & VM11 & VM42 \\
\hline 1-Hexadecanol & 22.32 & 9.5 & 11.24 & 242 & $\mathrm{C}_{16} \mathrm{H}_{34} \mathrm{O}$ & - & - & $*$ \\
\hline Hexacosyl acetate & 76.74 & 3.255 & 10.62 & 424 & $\mathrm{C}_{18} \mathrm{H}_{36} \mathrm{O}_{2}$ & $*$ & - & $*$ \\
\hline Tryphenylphosphine oxide & 81.63 & 11.549 & 26.23 & 278 & $\mathrm{C}_{18} \mathrm{H}_{15} \mathrm{OP}$ & $*$ & $*$ & $*$ \\
\hline 1,3-Propanediol, 2-methyl, dipropanoate & 81.21 & 2.368 & 3.39 & 202 & $\mathrm{C}_{9} \mathrm{H}_{21} \mathrm{O}_{6}$ & $*$ & $*$ & $*$ \\
\hline 1,4-Pentadiene & 67.88 & 6.846 & 15.45 & 68.12 & $\mathrm{C}_{5} \mathrm{H}_{8}$ & $*$ & $*$ & - \\
\hline Hydroxyurea & 88.13 & 5.317 & 6.66 & 76.05 & $\mathrm{CH}_{4} \mathrm{H}_{2} \mathrm{O}_{2}$ & $*$ & $*$ & $*$ \\
\hline Decyl trifluoroacetate & 71.59 & 0.130 & 12.38 & 282 & $\mathrm{C}_{12} \mathrm{H}_{21} \mathrm{~F}_{3} \mathrm{O}_{2}$ & - & $*$ & $*$ \\
\hline Pentadecane & 24.02 & 1.77 & 15.46 & 212.41 & $\mathrm{C}_{15} \mathrm{H}_{32}$ & $*$ & $*$ & $*$ \\
\hline 4-Ethyl-1-octyn-3-ol & 53.16 & 2.28 & 5.27 & 154 & $\mathrm{C}_{10} \mathrm{H}_{18} \mathrm{O}$ & $*$ & $*$ & $*$ \\
\hline Tridecane & 12.06 & 13.139 & 12.72 & 184 & $\mathrm{C}_{13} \mathrm{H}_{28}$ & $*$ & $*$ & $*$ \\
\hline Benzothiazole & 69.54 & 5.41 & 16.08 & 135.19 & $\mathrm{C}_{7} \mathrm{H}_{5} \mathrm{NS}$ & $*$ & $*$ & $*$ \\
\hline N,N-Dimethyldodecylamine & 42.16 & 3.39 & 14.09 & 213.41 & $\mathrm{C}_{14} \mathrm{H}_{31} \mathrm{~N}$ & $*$ & $*$ & - \\
\hline 1,3-Butadiene & 33.86 & 4.03 & 15.05 & 54.09 & $\mathrm{C}_{4} \mathrm{H}_{6}$ & $*$ & $*$ & $*$ \\
\hline Dodecane & 20.92 & 3.506 & 7.99 & 188 & $\mathrm{C}_{12} \mathrm{H}_{25}$ & $*$ & $*$ & $*$ \\
\hline 2-Undecanone & 26 & 6.32 & 18.06 & 170.29 & $\mathrm{C}_{11} \mathrm{H}_{22} \mathrm{O}$ & $*$ & $*$ & $*$ \\
\hline IR-(+)- $\alpha$-pinene & 61 & 2.38 & 7.55 & 136.24 & $\mathrm{C}_{10} \mathrm{H}_{16}$ & $*$ & $*$ & $*$ \\
\hline
\end{tabular}

a Asterisks (*) indicate VOC emitted by the Bacillus strain.

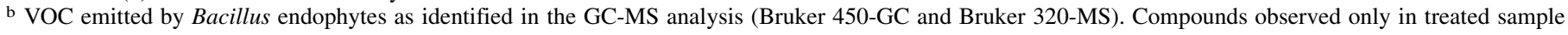
vials were selected for further biocontrol assay, and their selection was based on high relative peak area, availability, and maximum spectra similarity with that deposited in the National Institute of Standards and Technology (NIST) database.

c Spectra similarity of analyte compounds with those available in NIST library.

${ }^{d}$ Relative area of detected compounds as a percentage in reference to the total spectra peaks

e Retention time of the compounds in the GC-MS analysis.

f Molecular weight of detected compounds.

g Molecular formula of identified compounds. 
of selected host plants were detached using a sharp blade, rinsed with sterile distilled water, and aseptically air dried. Fungal hyphae plugs of S. sclerotiorum that had been prepared as described earlier were placed on the upper part of the leaf midvein, while their petioles were wrapped with wet cotton wool to prevent desiccation. The leaves were placed in square plates $(10$ by $10 \mathrm{~cm})$ and incubated at $25^{\circ} \mathrm{C}$ with a photoperiod cycle of $12 \mathrm{~h}$ (GXZ280D; YIQI). Fungal pathogenicity was scored after $72 \mathrm{~h}$ postinoculation (hpi) by measuring the diameter of the disease lesion. The experiment was replicated thrice in a completely randomized design arrangement.

Medium acidification assays. Cell-wall extracts of tomato plants were used to evaluate the impact of Bacillus VOC on the ability of S. sclerotiorum to produce OA (Poussereau et al. 2001). Tomato cell-wall extracts were obtained from 2-week-old seedling leaves that were blade blended into small pellets, then centrifuged at $1,000 \times g$ for $10 \mathrm{~min}$ and lyophilized (2-4 LD plus; CHRiST ALPHA) for $24 \mathrm{~h}$ before use. Two blocks (6 $\mathrm{mm}$ in diameter) of $S$. sclerotiorum mycelia prepared as described earlier were placed into $100 \mathrm{ml}$ of liquid $\mathrm{MSM}\left(\mathrm{KH}_{2} \mathrm{PO}_{4}\right.$ at $1 \mathrm{~g} / \mathrm{liter}, \mathrm{MgSO}_{4} \cdot 7 \mathrm{H}_{2} \mathrm{O}$ at $0.1 \mathrm{~g} / \mathrm{liter}, \mathrm{ZnSO}_{4}$ at $0.25 \mathrm{~g} / \mathrm{liter}, \mathrm{Fe}\left(\mathrm{SO}_{4}\right)_{2} \cdot 5 \mathrm{H}_{2} \mathrm{O}$ at $0.05 \mathrm{~g} / \mathrm{liter}, \mathrm{Cu}$ (SO4) $)_{2}$ at $0.05 \mathrm{~g} / \mathrm{liter}, \mathrm{MnSO}_{4}$ at $0.025 \mathrm{~g} /$ liter, and $\mathrm{H}_{3} \mathrm{BO}_{3}$ at $0.025 \mathrm{~g} /$ liter) supplemented with $2 \%$ freeze-dried tomato cell-wall pellets. The flasks containing VOC-untreated fungal mycelial blocks served as controls. The $\mathrm{pH}$ of the medium was adjusted to 7.0. Cultures were suspended at $25^{\circ} \mathrm{C}$ under constant agitation (180 rpm) with continual $\mathrm{pH}$ monitoring ( $\mathrm{pH} 700$; Eutech Instruments) every $12 \mathrm{~h}$ for $72 \mathrm{~h}$. Concentrations $(\mathrm{mM})$ of OA in liquid MSM flasks were estimated by the potassium permanganate $\left(\mathrm{KMnO}_{4}\right)$ titration method (Bateman and Beer 1965; Marciano et al. 1989). The above medium acidification assay was verified in bromophenol blue agar plates (Liang et al. 2015). PDA medium (20 ml) supplemented with bromophenol blue at $50 \mathrm{mg} / \mathrm{liter}$ was poured into 9-cm Petri plates. Fungal blocks ( $6 \mathrm{ml}$ in diameter) initially exposed to Bacillus VOC for $48 \mathrm{~h}$ were placed at the center of plates. Control plates contained VOC-untreated fungal plugs. The plates in triplicate were sealed and incubated at $25^{\circ} \mathrm{C}$. The trend of color change from blue to yellow as a signal of $\mathrm{pH}$ change was observed for $72 \mathrm{~h}$ at intervals of 12-h. The assays were performed at least three times.

Data analysis. Data on mycelial growth inhibition, sclerotia number and weight were subjected to one-way analysis of variance using SPSS software, version 20.0. Turkey's honestly significant difference test at $P=0.05$ was used to determine the difference between means. The data were reported as mean \pm standard error of the mean.

\section{RESULTS}

Identification and phylogeny trend of Bacillus endophytes. The Bacillus endophytes VM10, VM11, and VM42 were molecularly identified based on 16S rRNA and gyrA genes. The 16S rRNA gene of strain VM10 and VM11 was 99\% homologous to the 16S rRNA gene of B. velezensis strain LNHL1 (MG008635) and B. velezensis strain YJC-9 (MF499153), whereas the partial 16S rRNA gene of strain VM42 shared $99 \%$ homology to that of B. amyloliquefaciens strain BNS2 (KY681451). Based on the analysis of the gyrA gene sequence, VM10 and VM11 showed $96 \%$ sequence homology to the gyrA gene of B. velezensis strain sx016004 (CP018007), while strain VM42 exhibited $97 \%$ similarity to the gyrA gene of B. amyloliquefaciens strain FZB13 (FN652781). Also, a phylogenetic analysis based on $16 \mathrm{~S}$ rRNA and gyrA gene sequences revealed that these endophytic Bacillus strains fall in the clusters of B. amyloliquefaciens and B. velezensis (Fig. 1A and B). The sequences based on 16S rRNA and gyrA genes were deposited to the National Center for Biotechnology Information GenBank under accession numbers MG763620 (VM42), MG763619 (VM11), MG763618 (VM10), MG763615 (VM42), MG763616 (VM11), and MG763617 (VM10).

VOC and secondary metabolites mediated antifungal activity. Pathogenicity of S. sclerotiorum is certainly contributed by the presence and formation of healthy mycelia that can penetrate host plant cuticles (Kabbage et al. 2013). To test whether secondary metabolites produced by these Bacillus endophytes could negatively influence fungal mycelial growth, dual-culture and bicompartment assays were performed. The results revealed that the Bacillus endophytes possess both diffusible secondary metabolites and VOC in in vitro plate assays. Among the five tested Bacillus endophytes, three isolates impaired S. sclerotiorum mycelial growth in a dual-culture plate assay by forming zones between the fungus and Bacillus inoculum (Fig. 2A). Our results showed that B. velezensis VM10 produced the largest zone of inhibition $(33.3 \%$ reduction compared with the control) while $B$. amyloliquefaciens VM42 and B. velezensis VM11 inhibited fungal mycelial growth by 25.6 and $19.2 \%$, respectively. There was no statistically significant difference in mycelial growth observed in controls and Bacillus endophytes VM1 and VM21. Bacillus endophytes VM10, VM11, and VM42 were selected for further testing of their antifungal
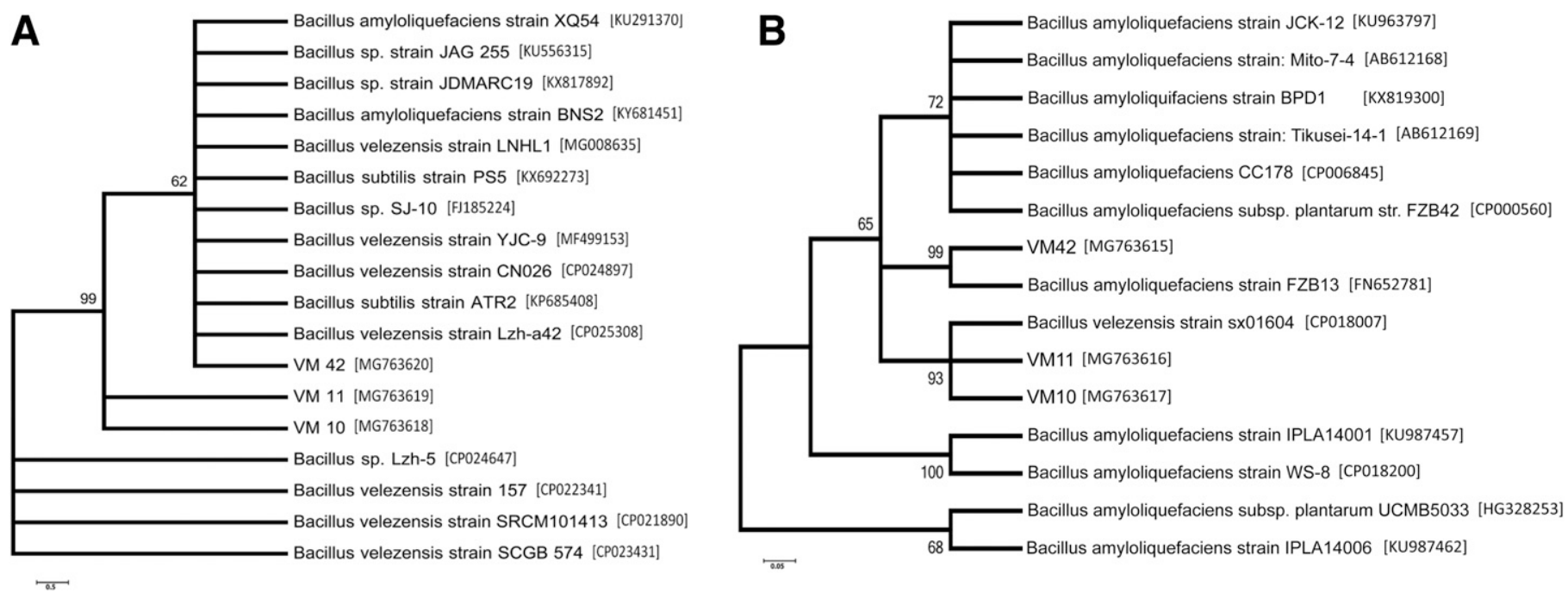

Fig. 1. Comparative sequence analysis of Bacillus endophytes based on A, $16 \mathrm{~S}$ ribosomal RNA and B, gyrA genes, showing a relationship with other Bacillus spp. sequences retrieved from the National Center for Biotechnology Information. Trees were constructed by the neighbor-joining method with branch significance indicated as a percentage of the branch nodes, supported by bootstrap for 1,000 replicates. 
activity against $S$. sclerotiorum, including the production of VOC. Among the three selected Bacillus endophytes, B. velezensis VM11 produced VOC with strong $S$. sclerotiorum growth inhibition by suppressing fungal mycelial by $86.6 \%$ compared with the control (Fig. 2B). B. velezensis VM10 and B. amyloliquefaciens VM42

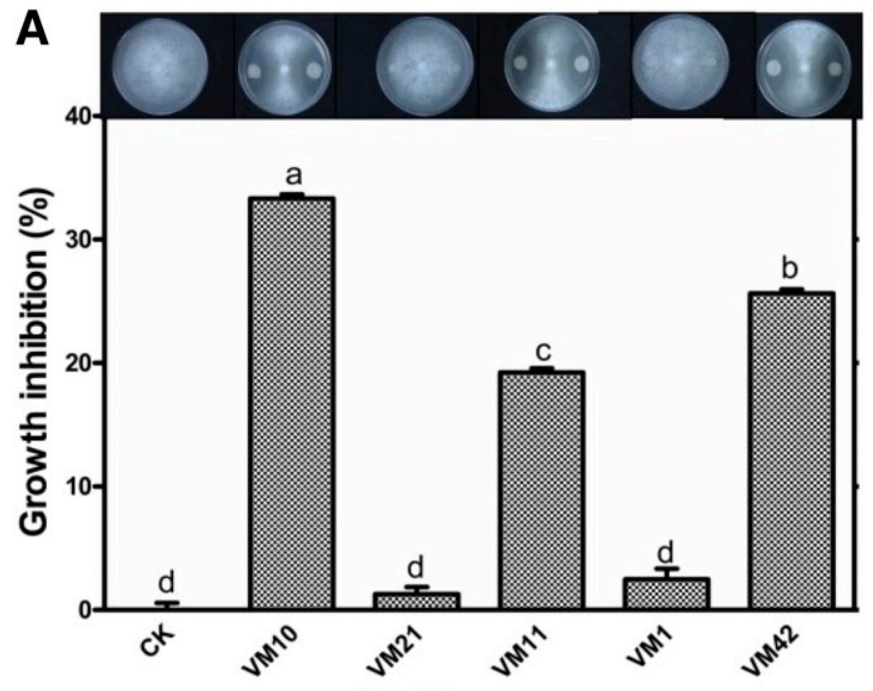

\section{Bacillus spp}

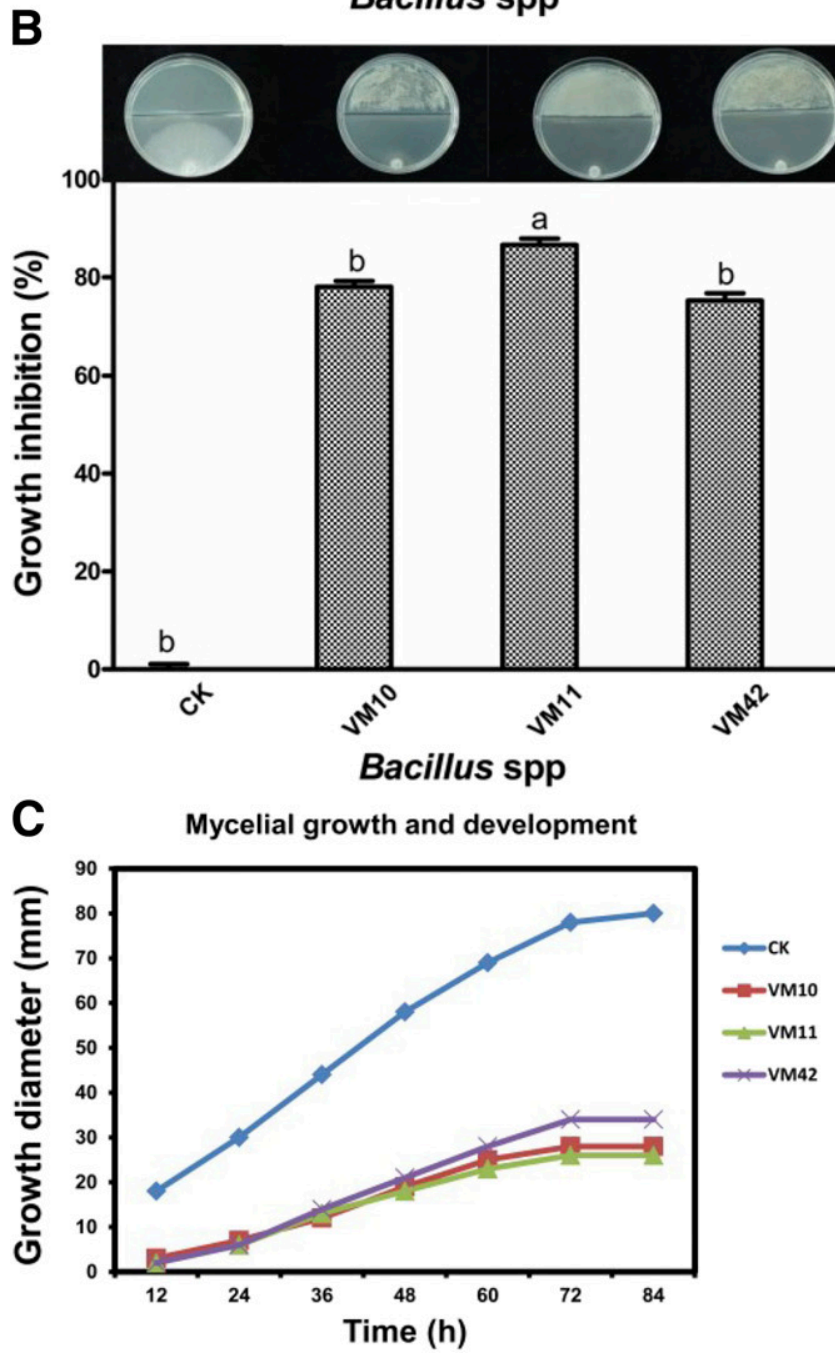

inhibited the growth of fungal mycelia by 78.1 and $75.24 \%$, respectively, compared with the control. Less-dense mycelia associated with a slower growth rate compared with the control were observed when the previously Bacillus VOC-treated fungal hyphae plugs were allowed to grow on fresh PDA for $84 \mathrm{~h}$. The

\section{Dual culture}
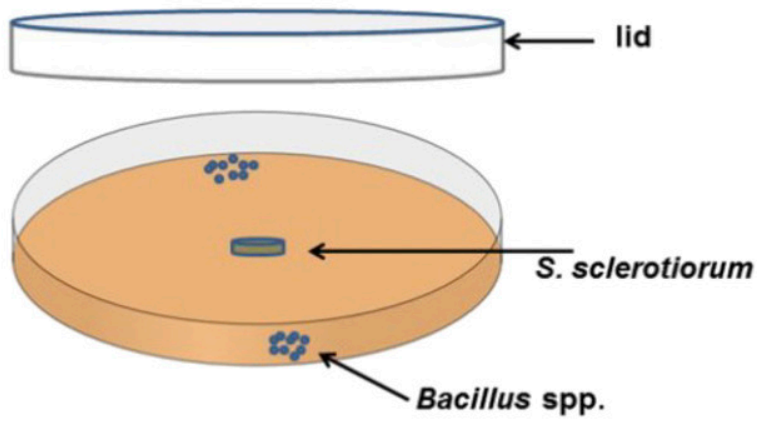

\section{Bicompartment}

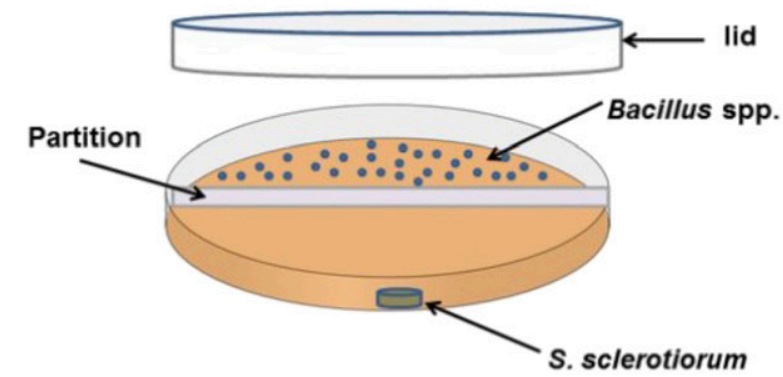

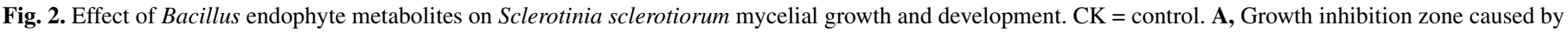

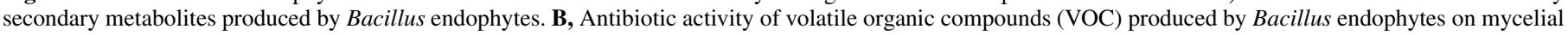

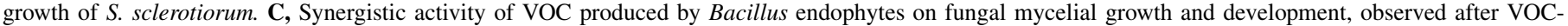
treated fungal mycelial plugs grown on a fresh potato dextrose agar. Different letters above error bars represent a significant difference between treatments. 
growth of fungal plugs in control plates was observed to progress normally from the onset of 12 hpi compared with Bacillus VOCtreated fungal hyphae plugs (Fig. 2C). These results indicated that these Bacillus spp. produced diffusible substances that could prevent fungal mycelia growth by creating inhibition zone between assayed organisms. Also, the VOC emitted by Bacillus spp. inhibited the growth of $S$. sclerotiorum mycelia when cultured together in the portioned plate or initially exposed to the VOC of Bacillus endophytes and thereafter grown on fresh PDA medium.

Sclerotia production was affected by Bacillus endophyte VOC. Sclerotia formed by S. sclerotiorum serve as an important inoculum, because they help the pathogen to survive in soils for several years without a host or favorable conditions for growth (Giorgio et al. 2015). Strong inhibitory activity exhibited against $S$. sclerotiorum mycelia growth prompted us to further investigate whether the VOC produced by Bacillus endophytes could affect sclerotial production and viability. The VOC emitted by Bacillus endophytes demonstrated their fungistatic effects toward $S$. sclerotiorum by complete inhibition of sclerotia production when Bacillus endophytes were incubated together with the pathogen in bicompartment plates for 14 days. There was a reduction in the number and weight when the nonfluffy fungal mycelia observed earlier on fresh PDA plates were allowed to mature. The number of sclerotia produced dropped to $62.9,54.7$, and $72.5 \%$ following the effects of VOC produced by B. velezensis VM11, B. velezensis VM10, and B. amyloliquefaciens VM42, respectively, compared with the control (Fig. 3A). Sclerotia weight recorded from fungal plugs previously treated with VOC produced by Bacillus strain VM11 was reduced to $50.2 \%$. The VOC of B. velezensis VM10 and B. amyloliquefaciens VM4 lowered sclerotia weight to 77.0 and $92.5 \%$, respectively (Fig. 3B). Moreover, healthy harvested sclerotia lost their germination ability after being incubated together with $5 \mu \mathrm{l}$ of Bacillus endophyte cultures. Surprisingly, the firmness of sclerotia was observed to deteriorate from hard to soft (spongylike) after exposure to Bacillus VOC for $48 \mathrm{~h}$. However, there was no visible difference in color between Bacillus VOC-treated and untreated sclerotia when they were cut cross-sectionally and observed under microscope (Fig. 3C). A set of VOC released by our Bacillus endophytes was revealed to interfere with fungal mycelia that led to the reduction in number and weight of sclerotia produced. Also, healthy sclerotia harvested from fungal plates which were prepared as described earlier lost their germination ability in the presence of Bacillus VOC.

Antibiotic activity of pure chemical volatiles on $S$. sclerotiorum. We focused our attention on the antifungal activity of 8 compounds (out of 16 analyzed in GC-MS) that were commercially available

A
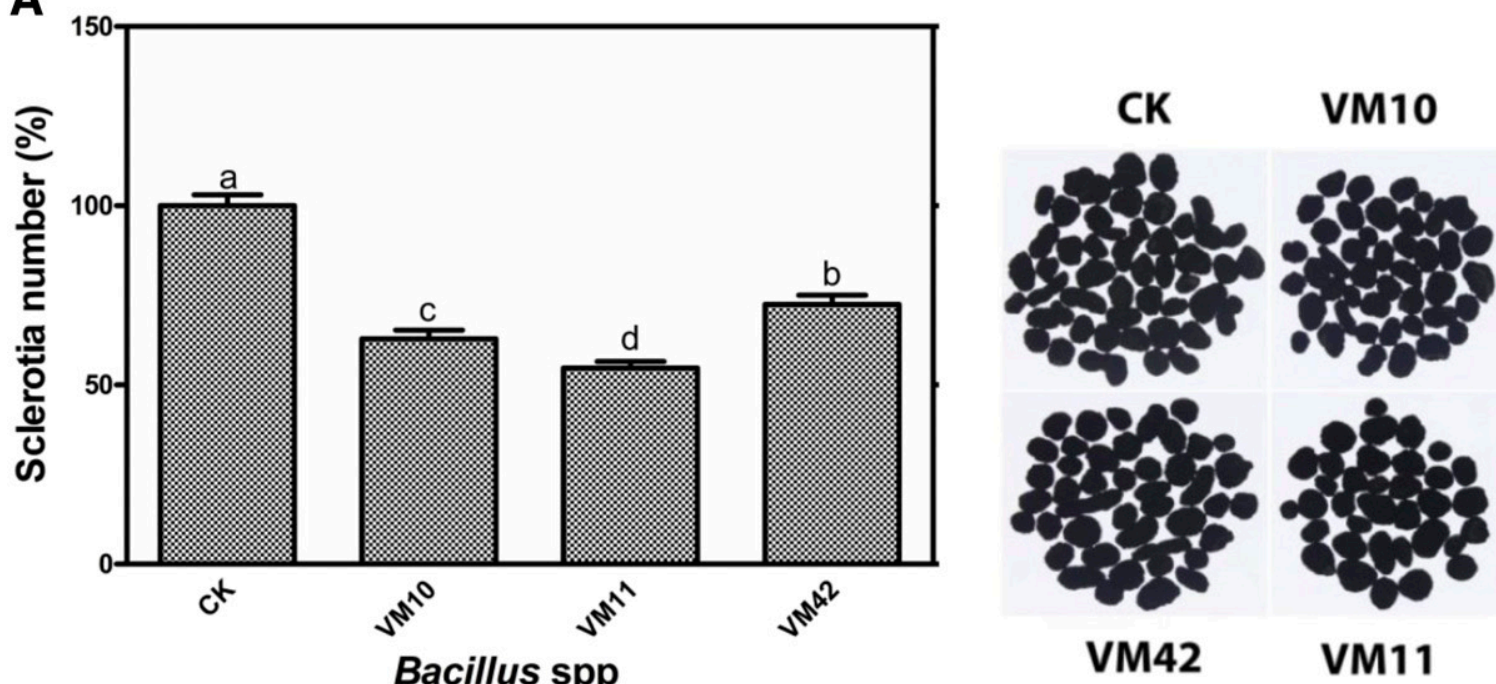

B

Bacillus spp

C
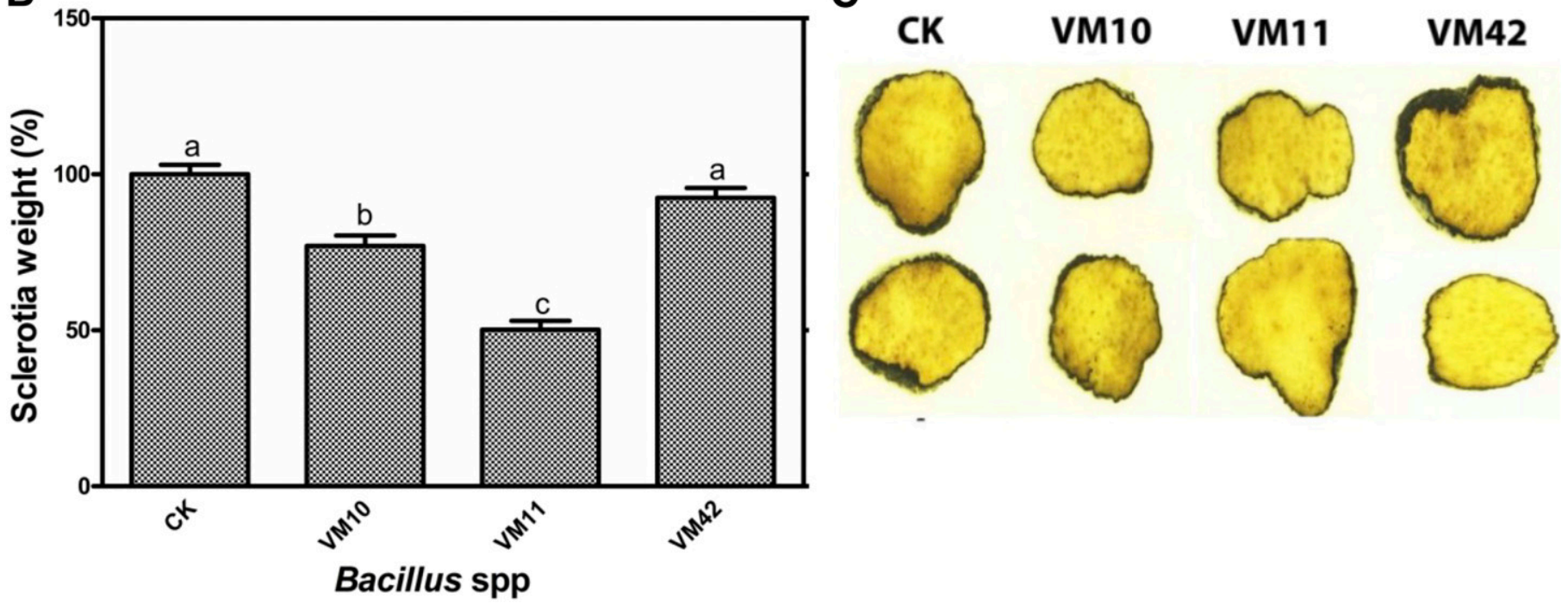

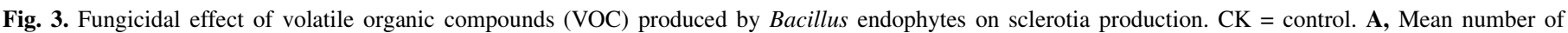

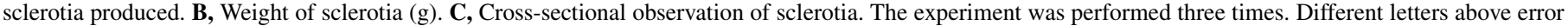
bars represent a significant difference between treatments. 
(Table 1). Pure synthetic chemical volatiles were observed to negatively affect the growth of fungal mycelia at different rates when applied at their highest concentrations (Fig. 4A). Four compounds (2-undecanone, benzothiazole, 1,3-butadiene, and N,Ndimethyldodecylamine) demonstrated strong antibiotic activity toward S. sclerotiorum mycelia, resulting in growth inhibition by $98.1,73.8,72.0$, and $58.9 \%$, respectively. Pentadecane and IR-(+)$\alpha$-pinene exhibited moderate fungal mycelial growth inhibition (19.6 to $34.6 \%)$, while the least inhibitory action was observed in dodecane and tridecane (6.4 and $11.2 \%$, respectively) (Fig. 4A).

A

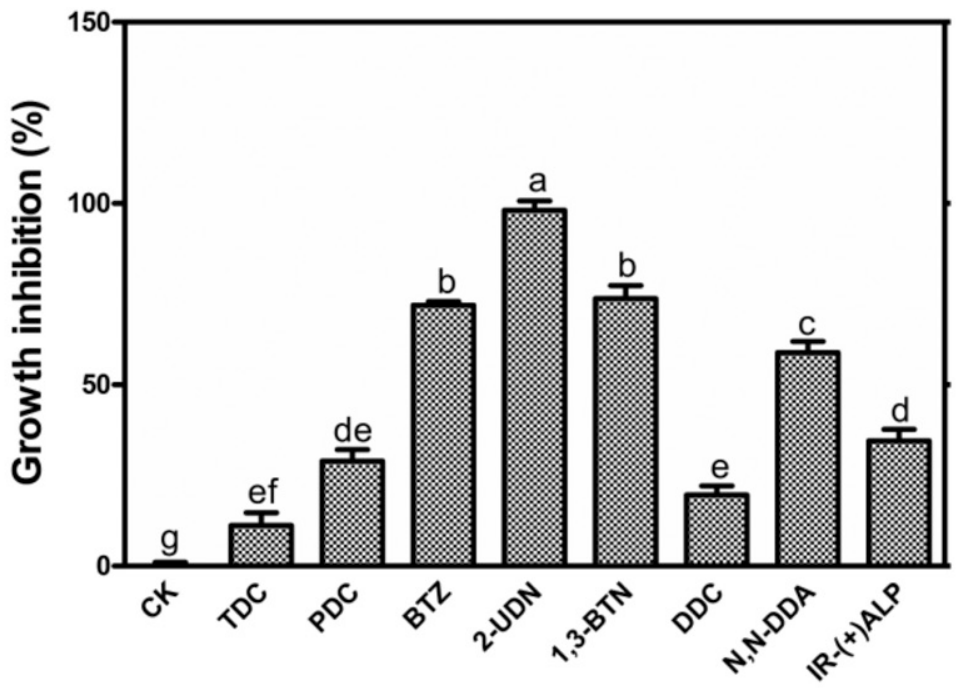

Synthetic VOCs
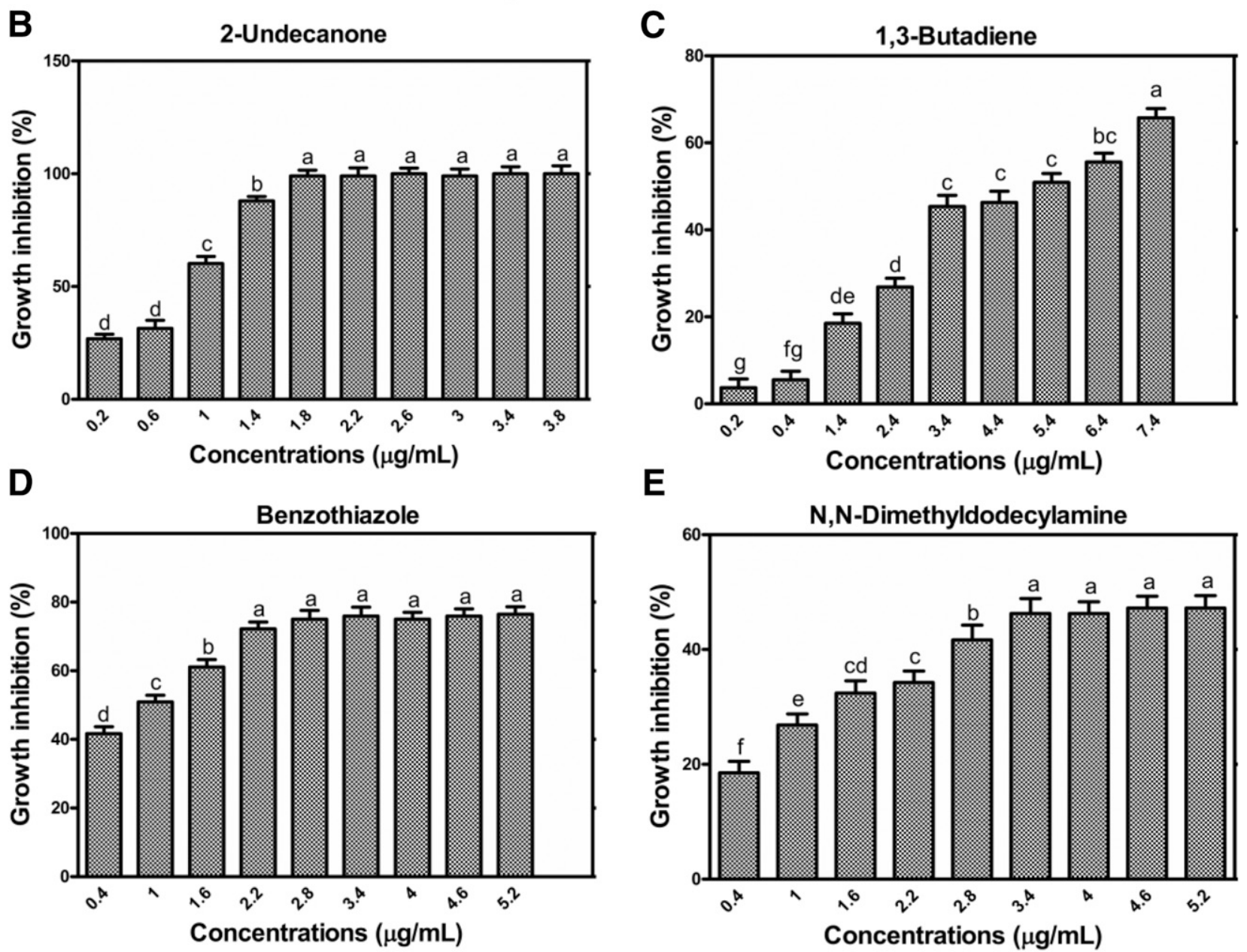

Fig. 4. Phytoinhibitory activity of synthetic volatile organic compounds (VOC) on mycelial growth of Sclerotinia sclerotiorum. A, Four synthetic VOC previously identified through gas chromatography-mass spectrometry analysis exhibited strong inhibition of fungal mycelial growth. Control $=\mathrm{CK}$, pentadecane $=\mathrm{PDC}$, tridecane $=$ TDC, benzothiazole $=$ BTZ, N,N-dimethyldodecylamine $=$ N,N-DDA, 1,3-butadiene $=1,3-\mathrm{BTN}$, dodecane $=$ DDC, 2-undecanone $=2$-UDC, and IR$(+)$ - $\alpha$-pinene $=$ IR-(+)ALP. B to E, Minimum inhibitory concentration of selected synthetic VOC. Different letters above error bars represent significant difference between treatments. 
MIC were evaluated for four chemicals that exhibited strong fungal growth inhibition. 2-Undecanone significantly inhibited fungal mycelial growth at a concentration of $0.2 \mu \mathrm{g} \mathrm{ml}^{-1}$ and completely suppressed fungal mycelial growth at a concentration of $1.8 \mu \mathrm{g} \mathrm{ml} \mathrm{m}^{-1}$. 1,3-Butadiene, benzothiazole, and $\mathrm{N}, \mathrm{N}-$ dimethyldodecylamine restricted fungal mycelial growth at a concentration of $0.2,0.2$, and $0.4 \mu \mathrm{g} \mathrm{ml}^{-1}$, respectively. $S$. sclerotiorum mycelial inhibition increased with the increase in applied concentration of 1,3-butadiene and benzothiazole. 2Undecanone and $\mathrm{N}, \mathrm{N}$-dimethyldodecylamine reached the static phase of growth at a concentration of 1.8 and $3.4 \mu \mathrm{g} \mathrm{ml}{ }^{-1}$, respectively (Fig. 4B to E). These observations indicated that four compounds (2-undecanone, benzothiazole, 1,3-butadiene, and N,Ndimethyldodecylamine) could be the main contributors of the antifungal activity in the VOC cocktail. These results also led us to further confirm their activity through performing more experiments, including the ability to trigger ROS accumulation in fungal mycelial cells.

Analysis of ROS induction. A high level of ROS concentration is harmful to cells and leads to cell death (Gu et al. 2017). To investigate the possible involvement of Bacillus VOC mixtures and pure individual volatile chemicals in inducing accumulation of ROS in S. sclerotiorum hyphae cells, a DCFH-DA stain kit was used. The VOC of Bacillus endophytes (VM10, VM11, and VM42) induced strong ROS production in $S$. sclerotiorum mycelial cells, which was indicated by illumination of sharp green fluorescence compared with the untreated control (Fig. 5). Green fluorescence was observed to span nearly the entire fungal mycelial network in both Bacillus VOC-treated plates compared with Bacillus VOC-untreated. All individual standard synthetic volatiles assayed triggered strong ROS on $S$. sclerotiorum mycelia at different sensitivity, notably higher than that of the control (Fig. 5). Therefore, these findings showed that the mixture of Bacillus VOC and individual pure chemicals could trigger ROS accumulation in fungal hyphae cells. Together

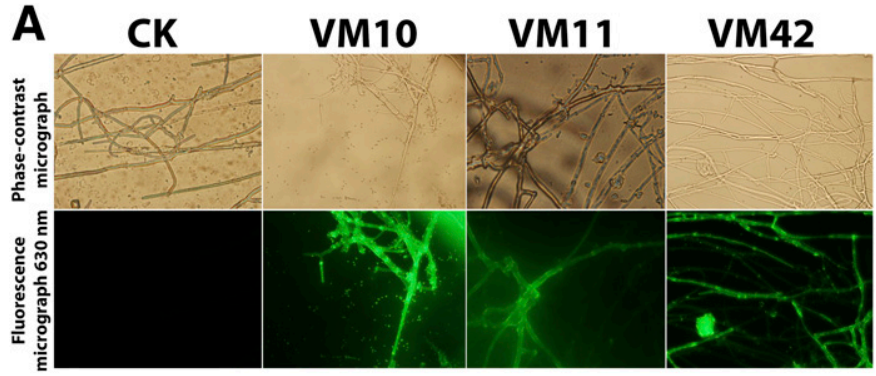

\section{B 1,3-BTN 2-UDN N,N-DDA BTZ}

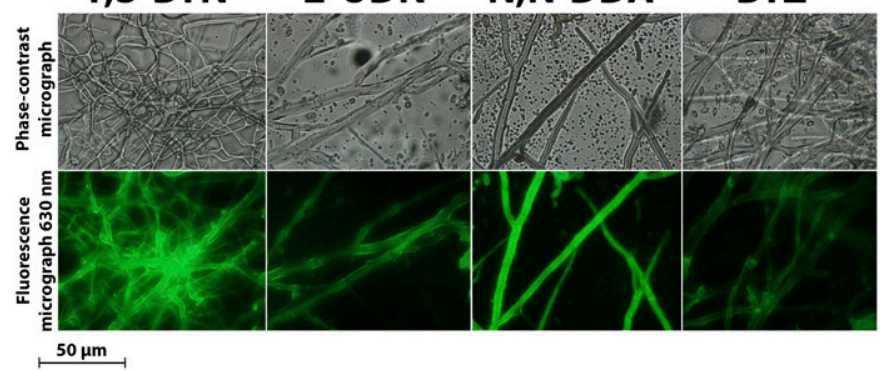

Fig. 5. Effect of synthetic and Bacillus endophyte volatile organic compounds (VOC) on the accumulation of reactive oxygen species (ROS) in fungal hyphae cells. ROS produced in fungal cells were detected based on dichlorodihydro-fluorescein diacetate (DCFH-DA) dye after $48 \mathrm{~h}$ of incubation of Sclerotinia sclerotiorum mycelia with A, $5 \mu$ l of overnight Bacillus endophytes culture or $\mathbf{B}, 5 \mu \mathrm{l}$ of the minimum inhibitory concentration of synthetic VOC in bicompartment plates. Green fluorescence illumination in treated samples signifies the accumulation of ROS in fungal cells. CK = control; VM10, VM11, and VM42 = Bacillus strains; 1,3-BTN = 1,3-butadiene; 2-UDN = 2-undecanone; N,N-DDA = N,N-dimethyldodecylamine; and BTZ = benzothiazole. with mycelial cell deformation observed in the ultrastructural analysis, these observations explained the reason for fungal mycelial growth inhibition when cocultured in bicompartment plates.

The VOC of endophytic Bacillus spp. caused morphological and ultrastructural alteration in $S$. sclerotiorum hyphae. Previously, the VOC produced by bacteria have been reported to affect ultrastructure and morphology of fungal hyphae, cells, and protoplasmic materials (Giorgio et al. 2015). To understand the extent of distortion exerted by VOC of B. velezensis VM11, SEM and TEM analyses were carried out to examine, in detail, the response of $S$. sclerotiorum hyphae from the cellular surface to the inner organelles. The VOC released by B. velezensis VM11 caused a range of abnormalities toward S. sclerotiorum hyphae compared with the VOC-untreated control in SEM analysis. Scanning electron micrographs captured from the VOC-untreated control displayed healthy, dense, and cylindrical hyphae (Fig. 6A to $\mathrm{C}$ ), whereas the Bacillus VOC-treated fungal hyphae were observed to have dramatic distortion, including thinness and rupture of some parts along the hyphae walls (Fig. 6D to F). Ultrastructural damages of $S$. sclerotiorum hyphae due to the VOC of B. velezensis VM11 were further observed using TEM. The VOC-untreated $S$. sclerotiorum showed normal hyphae, including well-preserved cell membranes with clear visible protoplasm (Fig. 7A to C). Fungal mycelia that were initially exposed to the VOC of B. velezensis VM11 displayed a number of abnormalities on cell membranes, mitochondria, nucleus, multivesicular structures, and cytoplasm. The distinctly visible disorders revealed were disruption of cell membranes, increased vacuoles size, and disorganized cytoplasmic materials to the extent of nondescript cell organelles (Fig. 7D to I). These microscopic observations led to the conclusion that the VOC of $B$. velezensis VM11 could damage fungal hyphae, cells, and cytoplasmic materials. These findings supported the observations
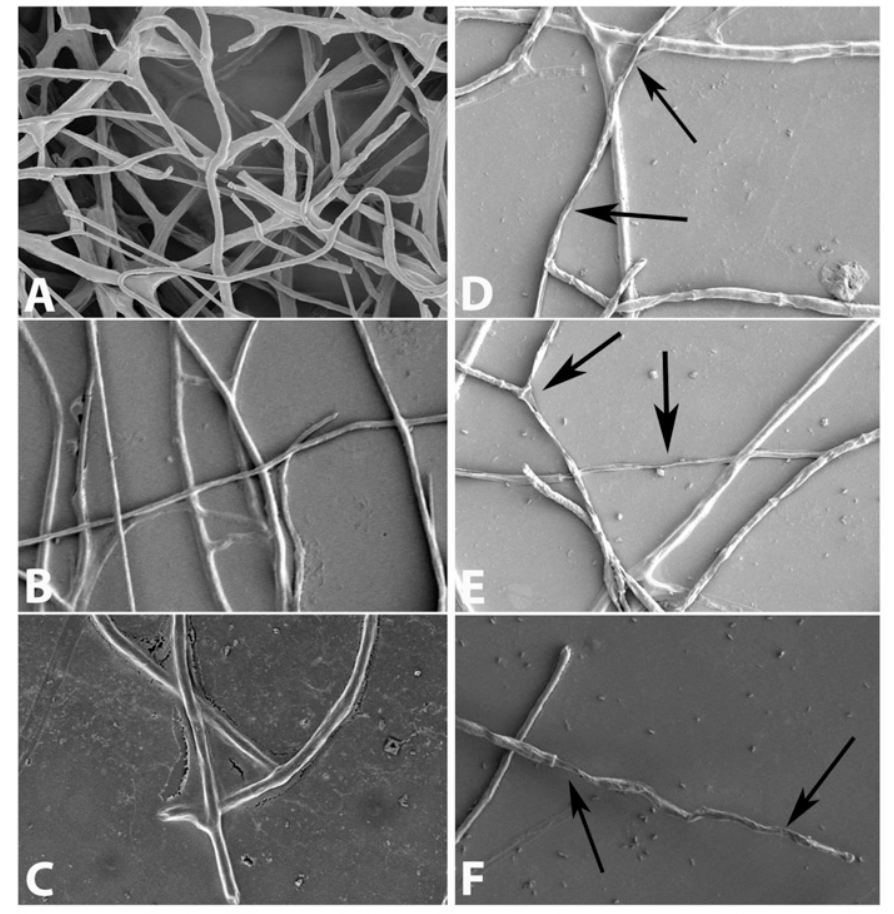

\section{$50 \mu \mathrm{m}$}

Fig. 6. Bacillus volatile organic compounds (VOC) emitted by Bacillus velezensis VM11 caused morphological distortion on fungal hyphae. Scanning electron microscopy analysis displayed $\mathbf{D}$ to $\mathbf{F}$, an evident alteration of Sclerotinia sclerotiorum hyphae walls resulting from treatment with the VOC of $B$. velezensis VM11 compared with $\mathbf{A}$ to $\mathbf{C}$, the VOC-untreated fungal hyphae. Arrowheads indicate the distorted parts of fungal hyphae. 
of fungal growth inhibition (Fig. 2), which could result from severe mycelial alteration caused by the VOC of Bacillus endophytes.

Pathogenicity test on host-plant leaves. Severe ultrastructural and morphological damage in fungal mycelia revealed in TEM and SEM analysis, coupled with the retarded mycelial growth in bicompartment plates, prompted us to investigate whether this fungal pathogen could still cause disease to host plants after exposure to the VOC produced by B. velezensis VM11. The pathogenicity assay was performed on detached leaves of representative host plants to assess the effectiveness of VOC produced by isolate VM11 to control Sclerotinia rot disease. Although preexposure to B. velezensis VM11 VOC did not completely inhibit disease development, significantly reduced lesion size compared with the untreated control was observed. A fungal hyphae plug initially treated with VOC emitted by B. velezensis VM11 produced limited lesions on all tested host-plant leaves $72 \mathrm{hpi}$, compared with VOCuntreated fungal hyphae plugs (Fig. 8A). The VOC-untreated fungal hyphae plug produced light-brownish lesions which spread fast to the margin of host-plant leaves compared with the treated fungal mycelia. Whereas 24-hpi VOC-untreated S. sclerotiorum hyphae plugs had produced significant disease lesions on the leaves, the VOC-treated fungal plugs produced approximately the same size of disease lesion $72 \mathrm{hpi}$ (Fig. 8B). The biocontrol assay revealed that disease progression was significantly lowered on the host-plant leaves challenged with fungal plugs preexposed to B. velezensis VM11 VOC compared with the control.

Bacillus VOC lowered OA produced by S. sclerotiorum. OA released by $S$. sclerotiorum during the early stages of hostpathogen interaction has been reported to be the main pathogenicity determinant (Williams et al. 2011) through modulating host environment, thus triggering the release of degrading enzymes. The first evidence that the VOC of Bacillus endophytes affected $S$. sclerotiorum in the accumulation of OA was observed on PDA medium supplemented with bromophenol blue. Bromophenol blue is an acid-base indicator, which emits blue color at $\mathrm{pH} \geq 4.6$ and yellow color at $\mathrm{pH} \leq 4.6$ (Kreft and Kreft 2009). In this study, yellow coloration was visible in plates containing VOC-untreated fungal plugs within 24 hpi and was also accompanied by a high growth rate compared with the VOC-treated fungal plugs (Fig. 9A). The VOC-treated fungal plugs were unable to acidify the medium at

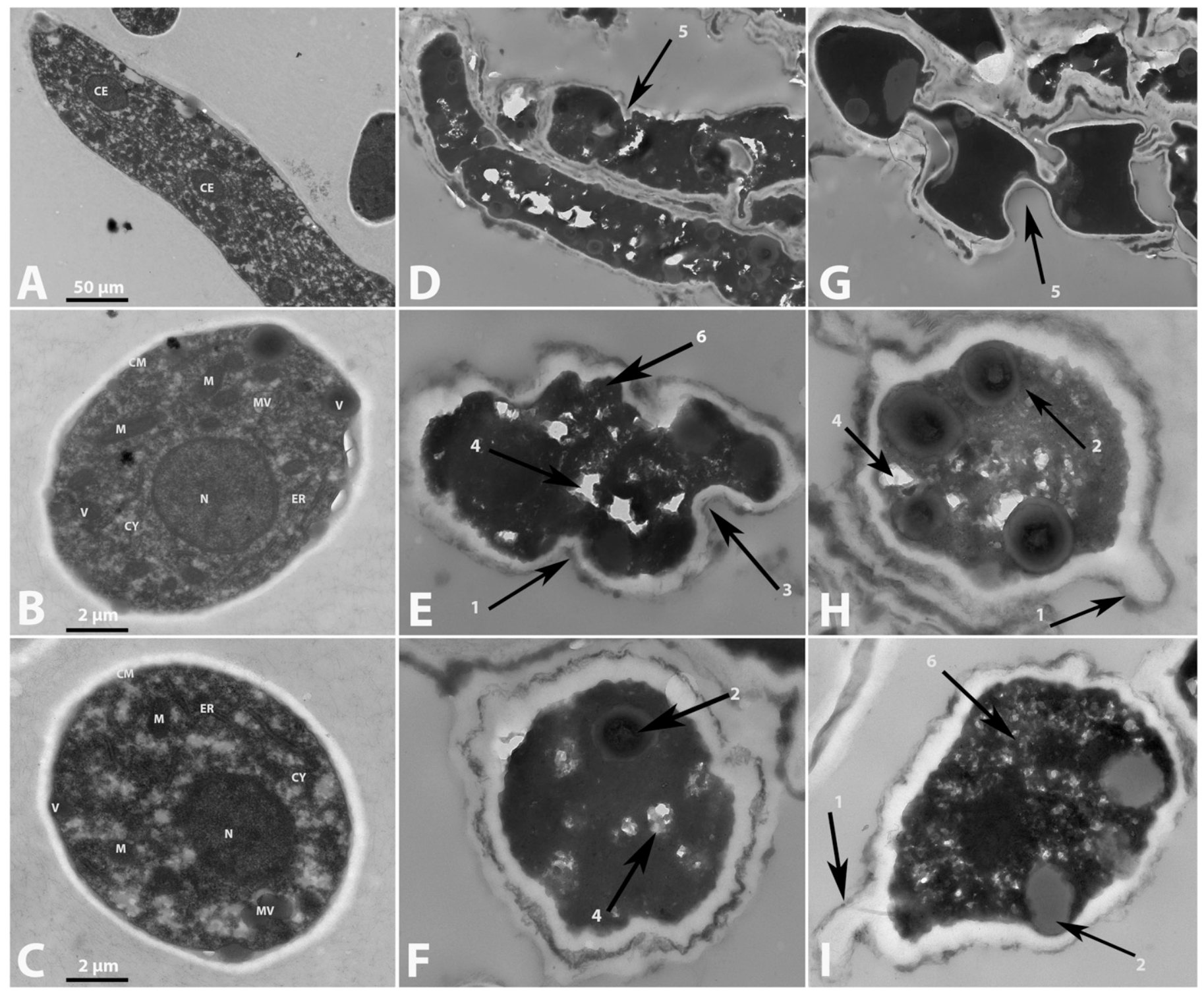

Fig. 7. Transmission electron microscopy analysis revealed ultrastructural malformation in Sclerotinia sclerotiorum hyphae walls and cell and organelle membranes caused by the volatile organic compounds (VOC) produced by Bacillus velezensis VM11. Compared with A to C, the VOC-untreated S. sclerotiorum hyphae, D to I, the VOC-treated hyphae demonstrated prominent abnormalities, including 1, loosening of the cell walls; 2, swelling of vacuoles; 3, loss of cell integrity; 4, displacement of multivascular; 5 , disintegration of the hyphae walls; and 6 , movement of cytoplasmic materials. $\mathrm{M}=$ mitochondria, $\mathrm{MV}=$ multivescular, $\mathrm{CY}=$ cytoplasm, $\mathrm{ER}=$ endoplasmic reticulum, $\mathrm{N}=$ nucleus, $\mathrm{V}=$ vacuole, $\mathrm{CM}=$ cell membrane, and $\mathrm{CE}=$ cell. 
$48 \mathrm{hpi}$, as shown by blue color retention compared with the control. Little indication of medium acidification in VOC-treated fungal disc plates was observed at $72 \mathrm{hpi}$, accompanied by weak and nonfluffy mycelia (Fig. 9A). To further confirm whether the VOC produced by Bacillus endophytes could affect $S$. sclerotiorum in the production of OA, liquid medium supplemented with hostplant extracts was used (Poussereau et al. 2001). Liquid medium supplemented with $2 \%$ tomato cell-wall extracts demonstrated that the fungal hyphae plugs treated by the VOC of Bacillus endophytes could not lower the $\mathrm{pH}$ of the medium at the same rate as VOCuntreated fungal hyphae plugs (Fig. 9B). The instant dropping of $\mathrm{pH}$ in flasks inoculated with VOC-untreated fungal hyphae plugs was observed within $12 \mathrm{hpi}$, which continued to drop until $36 \mathrm{hpi}$. From $36 \mathrm{hpi}$, the $\mathrm{pH}$ was constantly decreased further to 4.4 at the end of 72 hpi. For the fungal plugs exposed to Bacillus VOC, the medium $\mathrm{pH}$ began to decrease after $48 \mathrm{hpi}$ at a slower rate compared with untreated fungal hyphae plugs. Proportionally with the $\mathrm{pH}$ dropping rate, $\mathrm{OA}$ accumulation was observed to increase at an increasing rate from 12 to $60 \mathrm{hpi}$ and further proceed at a decreasing rate to 72 hpi (Fig. 9C). The observation from the above two medium acidification assays revealed that a fungal pathogen previously subjected to Bacillus endophyte VOC could not acidify media at the same rate as an untreated control, indicating low OA production.

\section{DISCUSSION}

Despite vast documentation detailing the mechanisms of host plant invasion and colonization, $S$. sclerotiorum remains a remarkable challenge to understand and control its infection mechanisms. Therefore, having a promising, alternative, biocontrol-based approach

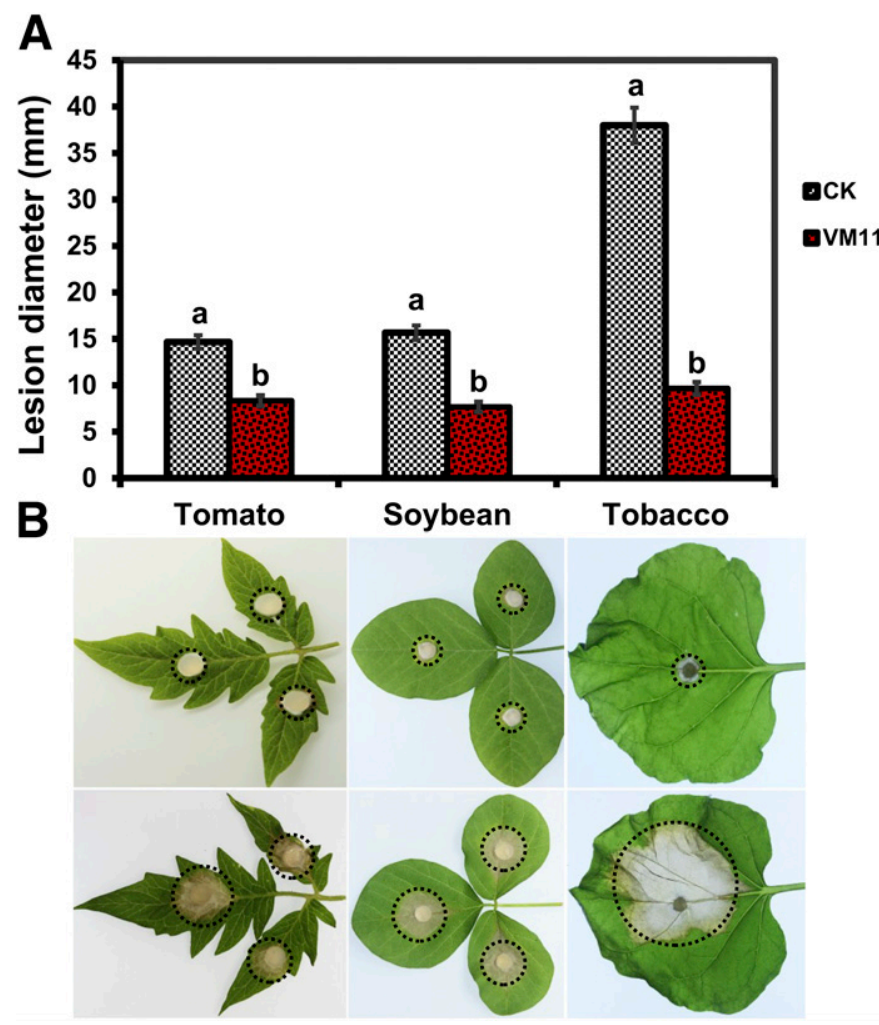

Fig. 8. Biocontrol efficacy of volatile organic compounds (VOC) of Bacillus velezensis VM11 to control Sclerotinia rot disease. Representative host plants were inoculated with either pathogen hyphae plug treated with the VOC of $B$. velezensis VM11 or VOC-untreated hyphae plugs (CK), and incubated at $25^{\circ} \mathrm{C}$ for $72 \mathrm{~h}$. A, Lesion diameters were greater in leaves challenged with the VOCuntreated fungal plugs compared with the VOC-treated fungal plugs. B, A clear difference of lesion size between VOC-treated and untreated was conspicuous in both assayed host-plant leaves. for this broad-host phytopathogen is virtually essential for global food production. Bacillus endophytes have been recently considered to be of high potential in a pool of biological control agents, and have been found in nearly all plants which have been studied, ranging from woody trees to herbaceous crops (Posada and Vega 2005). The existence of more than 300,000 plant species, while only a few of these plants have ever been explored, gives us an opportunity for exploration of new and diverse beneficial endophytic microorganisms with agricultural and nonagricultural potentials (Mitchell et al. 2010).

In this study, we characterized three Bacillus endophytes which were isolated from maize seed and identified as B. amyloliquefaciens (VM42) and B. velezensis (VM10 and VM11), based on 16S rRNA and gyrA gene sequence analysis. These strains produced diffusible substances, which repressed $S$. sclerotiorum mycelial growth at different sensitivity. The potentials of antimicrobial activity displayed by Bacillus spp. have been documented in many findings (Tahir et al. 2017; Yuan et al. 2013; Zhao et al. 2014). For example, B. amyloliquefaciens isolated by Wu et al. (2014b) was reported to possess broad-spectrum antimicrobial activity against phytopathogens such as Fusarium oxysporum f. sp. cucumerinum, F. oxysporum f. sp. niveum, Rhizoctonia solani, F. oxysporum f. sp. cubense, and Verticillium dahliae Kleb. Also, its culture filtrates and cell suspensions could decrease disease severity caused by S. sclerotiorum on canola leaves. B. amyloliquefaciens strain NJN-6 produced metabolites that had dual functions, including phytostimulation and antimicrobial activity, against several soilborne pathogens (Yuan et al. 2013; Zhao et al. 2014). However, in this work, focus was to assess the biocidal effects of VOC emitted by Bacillus isolates against the ascomycete $S$. sclerotiorum.

It is now apparent that bacteria generate a set of VOC that have synergistic activity against multiple plant pathogens (Fernando et al. 2005; Wan et al. 2008). In this study, the three Bacillus endophytes (VM10, VM11, and VM42) strongly affected S. sclerotiorum mycelial growth, which resulted in less dense and weak mycelial mat. Six bean-associated bacteria not only produced diffusible compounds but also produced VOC that had a synergistic effect against soilborne pathogen S. sclerotiorum strain USB-F593 (Giorgio et al. 2015). The findings by (Tahir et al. 2017) also showed that the VOC emitted by B. amyloliquefaciens FZB42 and B. artrophaeus LSSC22 were responsible for robust growth inhibition of $R$. solacearum in in vitro and protected tobacco plants from Bacillus wilt disease in a pottedplant experiment. The VOC produced by $S$. platensis F-1 reduced the damage of leaf blight disease of a canola crop caused by necrotroph S. sclerotiorum (Wan et al. 2008). In this report, the blend of VOC produced by Bacillus endophytes exerted strong interference with fungal mycelia which subsequently affected number and weight of sclerotia produced. The malfunction of fungal mycelia which resulted from Bacillus VOC may contribute to explain the production of unhealthy and decreased numbers of sclerotia. However, healthy sclerotia lost their viability in vitro when cocultured with Bacillus endophytes in bicompartment plates. The reports of Kai et al. (2009) and Fernando et al. (2005) also showed that the VOC emitted by Bacillus spp. could inhibit sclerotia germination, although the underlying mechanism is still unknown. B. cereus SC-1 inhibited sclerotia germination and reduced their viability below 2\% compared with the control (Duncan 2003). Other reports have shown negative effects of Bacillus VOC on fungi physiological functions, including sporulation, spore germination, sclerotial development, and mycelial growth (Fitter and Garbaye 1994; Mackie and Wheatley 1999; Vespermann et al. 2007). Our report suggests that there was a possibility that these VOC of Bacillus endophytes sabotaged sclerotia melanin by reacting with oxidation products of tyrosin and dehydroxyphenol compounds which largely constitute sclerotia melanin (Ellil 1999). The inhibitory activity observed in fungal mycelial growth in this study is the result of a mixture of VOC produced by the Bacillus endophytes. However, this set of VOC contains major compounds which largely mediated the antifungal action. 
GC-MS analysis revealed that the Bacillus endophytes could produce 16 bioactive VOC, 8 of which were commercially available. The eight synthetic VOC were observed to significantly inhibit $S$. sclerotiorum mycelial growth. Indeed, four compounds (2-undecanone, benzothiazole, 1,3-butadiene, and $\mathrm{N}, \mathrm{N}$-dimethyldodecylamine) demonstrated outstanding toxic effects on fungal mycelial growth. In this study, benzothiazole was shown to inhibit the growth of fungal mycelia at an MIC of $0.2 \mu \mathrm{g} / \mathrm{ml}$. Benzothiazole has also been articulated in previous findings for its antifungal characteristics against $S$. sclerotiorum hyphae and sclerotia development (Fernando et al. 2005). Its strong fungicidal activity was suggested to be contributed by the presence of a sulfur ion that has been used for decades as a primary compound in commercial synthetic fungicides. Biological functions of benzothiazole were also reported by Stokes et al. (2013) for inhibition of growth on a range of important clinical bacteria, including staphylococci, streptococci, enterococci, and Clostridium difficile, at a concentration of $0.25 \mu \mathrm{g} / \mathrm{ml}$. On the other hand, 2-undecanone strongly affected growth and development of fungal mycelia at an MIC of $0.2 \mu \mathrm{g} / \mathrm{ml}$ and completely inhibited fungal growth at a concentration of $1.8 \mu \mathrm{g} / \mathrm{ml}$. Its adverse reaction on the fungal cell wall has been linked with its ability to permeate cell membranes, the activity mediated by the lipophilic nature of acyl carbons that are ordinarily optimal when the compound contains 9-14 carbons (Dimock et al. 1982). Giorgio et al. (2015) confirmed this finding when pure 2-undecanone lysed red blood, whereas Ntalli et al. (2016) reported that, the nematicidal effects of 2-undecanone were neither through cuticle nor in somatic muscles but instead via pseudocoel cells, revealing the activity of this compound on biological membranes. 1,3-Butadiene and N,N-dimethyldodecylamine have been reported to possess multiple benefits, including antibiotic activity (Tahir et al. 2017). A combination of N,N-dimethyldodecylamine and its close relatives ( $\mathrm{N}, \mathrm{N}$-dimethyloctylamine and $\mathrm{N}, \mathrm{N}$-dimethylbutylamine) was found to be useful in both biocontrol of different phytopathogens
A

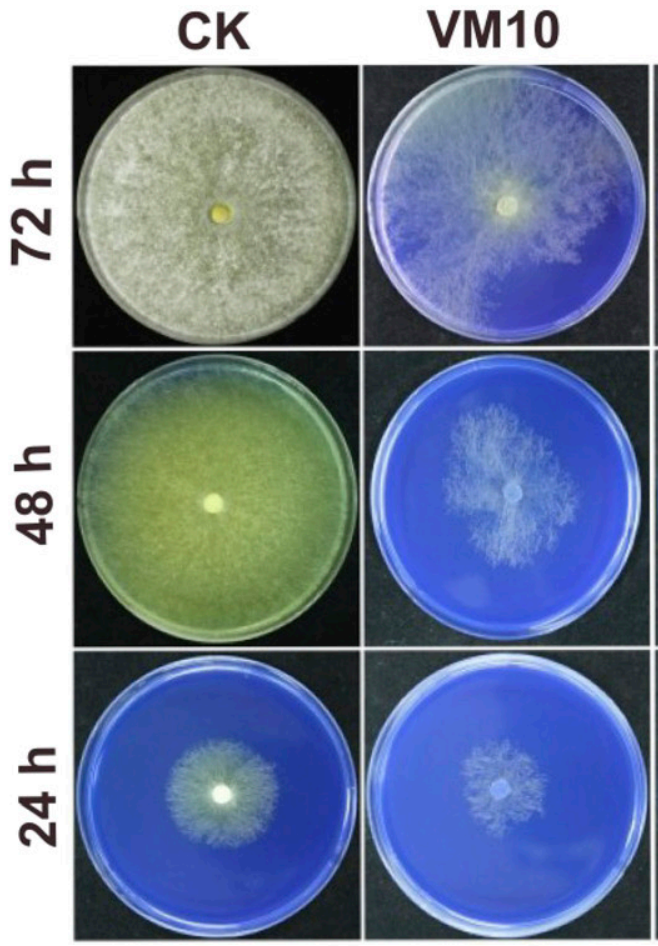

B

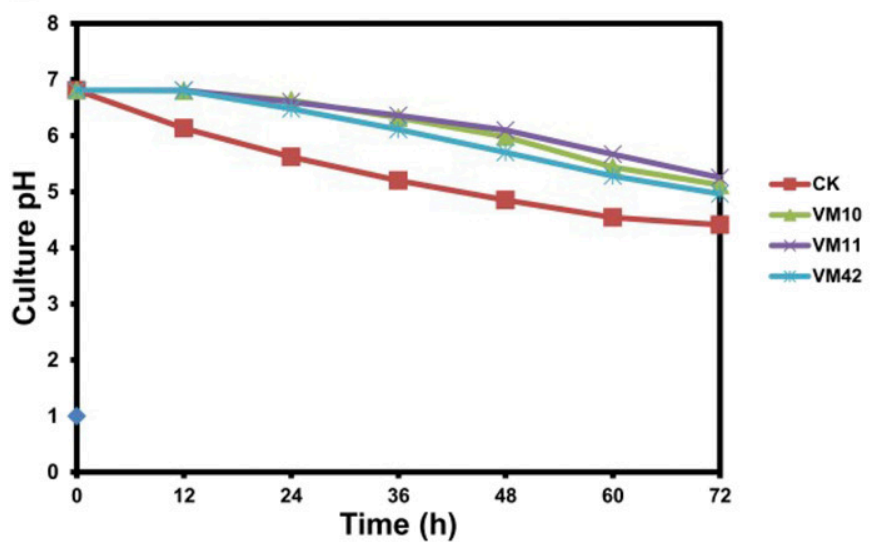

VM11
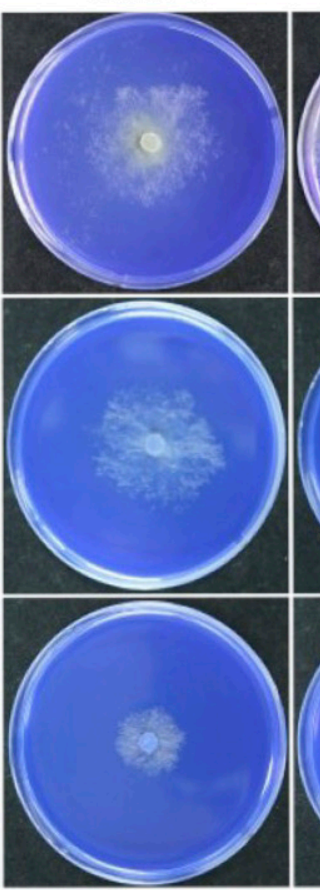

C

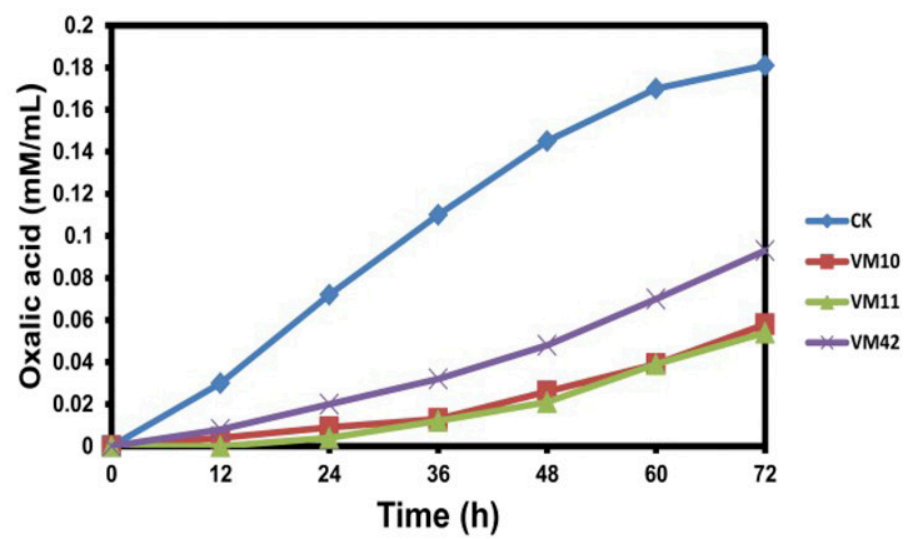

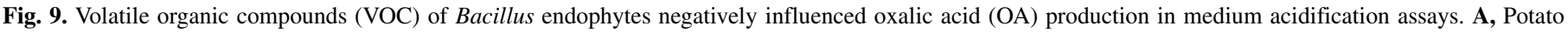

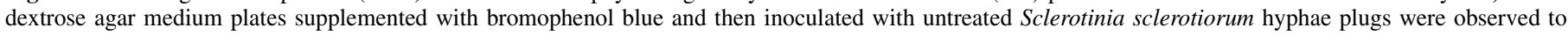

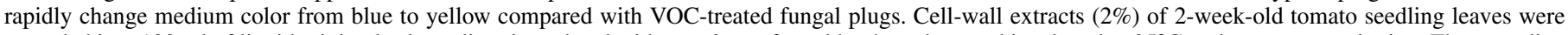

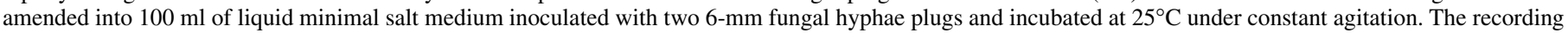

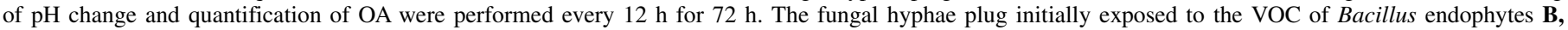
lowered the medium $\mathrm{pH}$ and $\mathbf{C}$, accumulated $\mathrm{OA}$ into the culture mixture at a lower rate compared with VOC-untreated fungal hyphae plugs. 
and production of novel cationic dyes for textile industrial use (Ma et al. 2003). In the present work, four VOC were the major contributors for fungicidal action, mediated by a mixture of Bacillus VOC, although other compounds also significantly contributed to the effects.

In this study, we showed that both synthetic VOC and a blend of VOC produced by Bacillus endophytes triggered ROS accumulation in S. sclerotiorum hyphae cells which possibly resulted from oxidative stress. Oxygen molecules are known to form highly potent oxidants along with unstable ROS during energy or electron transfer reactions in cells (Mitchell et al. 2010). The resultant energy transfer leads to the formation of singlet oxygen, whereas electron transfer results in a sequential reduction of unstable oxygen to superoxide $\left(\mathrm{O}_{2}\right)$, hydrogen peroxide $\left(\mathrm{H}_{2} \mathrm{O}_{2}\right)$, and hydroxyl radicals $\left(\mathrm{OH}^{*}\right)$, which are highly reactive with cellular macromolecules (Finkel and Holbrook 2000; Heller and Tudzynski 2011). Our report conforms precisely to the findings of Mitchell et al. (2010) that there was a direct correlation between ROS accumulation and detrimental effects of fungal cellular components, including DNA. The VOC produced by Bacillus endophytes in this study might have exerted oxidative stresses like that of UV radiation, extreme temperatures, desiccation, or heavy metals which forcefully accumulate ROS beyond the organism's antioxidant capability.

We hypothesized that the VOC of Bacillus endophytes might have fungicidal effects toward $S$. sclerotiorum hyphae but, when regrown on a fresh PDA medium, hyphae were observed to regain their growth momentum, although at a lower rate compared with the control. Survival of few fungal hyphae possibly would be due to different sensitivity of fungal mycelia upon exposure to Bacillus VOC that might have led other fungal hyphae to be resistant. Also, the enzymatic and nonenzymatic antioxidant mechanisms involved in suppressing elevated intracellular ROS levels during oxidative stress might be the probable cause of this observation. The enzymatic antioxidant reaction involves superoxide dismutase, which dismutates $\mathrm{O}_{2}$ to $\mathrm{H}_{2} \mathrm{O}_{2}$, whereby the intermediate reaction is detoxified into $\mathrm{H}_{2} \mathrm{O}$ by the action of glutathione peroxidase and catalase. The cell can also produce small soluble molecules that are prompted by elevated ROS, thus alleviating oxidant levels from cell solution (Aguirre et al. 2005; Fialho et al. 2014; Heller and Tudzynski 2011).

SEM and TEM analyses revealed prominent morphological and ultrastructural disruption of $S$. sclerotiorum hyphae treated with VOC of B. velezensis VM11 compared with untreated controls. Deformed cell structure and inclusion of organelle material in the cytoplasm resulted from membrane damage, indicating the possibility of cells and organelle membranes to be potential targets for the VOC emitted by B. velezensis VM11. The presence of 2undecanone and benzothiazole substances in the VOC mixture could be the reason for membrane distortion because these compounds have been shown in previous findings to permeate and severely damage biological membranes (Giorgio et al. 2015; Ntalli et al. 2016; Tahir et al. 2017).

Upon contact with the host-related environment, S. sclerotiorum begins producing $\mathrm{OA}$ that enhances favorable conditions for the release of hydrolytic enzymes. The biocidal action of VOC confirmed by B. velezensis VM11 in this report is thought to be related to the previously reported Bacillus VOC that were believed to enter fungal membranes by incorporating themselves in the aqueous phase of cell membranes through hydrogen bonding (Voda et al. 2004). The forces created during this bonding disturb the aqueous solution of cell membranes, which also interferes with cell physiology and functions (Kim et al. 2007; Kubo et al. 1995; Voda et al. 2004). Despite the structural damage caused by VOC of B. velezensis VM11, we speculate that these VOC might have tangled oxaloacetate hydrolase $(\mathrm{OAH})$, resulting in low OA production. More research work is required in this area to understand the underlying putative interaction mechanisms between Bacillus VOC and OAH of S. sclerotiorum.
The biocontrol activity observed in the detached-leaf assay is an indication of little or weak compatibility between VOC-treated phytopathogens and their hosts that might be caused by the inability to produce sufficient OA, which is crucial for disease establishment. Substantial reduction of virulence on the detached leaves demonstrated by the pathogens treated with VOC of $B$. velezensis VM11 let us believe that they can be a potential strategy to control diseases caused by S. sclerotiorum. Our report coincides with the findings by (Huang et al. 2012) that the VOC of $B$. cereus protected tobacco plants against gray mold disease of B. cinerea. Also, the protective activity of VOC of $S$. globisporus against $B$. cinerea in tomato fruit has been demonstrated ( $\mathrm{Li}$ et al. 2010). However, the limited lesions on host plants observed in this study could be caused by fungal hyphae which resisted damage from Bacillus VOC or OA-independent virulence effectors. The few fungal mycelia that resisted damage as observed in SEM analysis could possibly initiate colonization by releasing OA but might be insufficient for full virulence. These results also support the previous findings (Liang et al. 2015) reporting the existence of other factors beyond OA that may significantly influence S. sclerotiorum pathogenesis during the host-pathogen interaction. Ss-ITL and Sc-Cm1 protein effectors are known to be involved in host-defense avoidance while functioning independently of OA to establish early infection (Kabbage et al. 2013). However, many more protein effectors have been identified through bioinformatics approaches, with an ability to suppress host defense systems by thrusting their virulence effectors to the hosts, independently of OA (Djamei et al. 2011; Kabbage et al. 2013; Zhu et al. 2013).

In conclusion, the data presented in this work revealed that a set of VOC emitted by Bacillus endophytes caused ultrastructural and morphological damage to the phytopathogen S. sclerotiorum, which was observed to stretch its hyphae limits, resulting in abnormal growth and total failure of sclerotia germination. More importantly, we report the first accounts of the ability of Bacillus endophyte VOC to suppress OA production levels to a threshold whereby it could not establish full virulence on the leaves of host plants. This report not only opens up a new research front but also highlights the antagonistic biochemistry between Bacillus VOC and the virulence arsenals of $S$. sclerotiorum. It also presents a new prospect to improve biochemicals to their full potential in controlling plant diseases caused by $S$. sclerotiorum.

\section{LITERATURE CITED}

Aguirre, J., Ríos-Momberg, M., Hewitt, D., and Hansberg, W. 2005. Reactive oxygen species and development in microbial eukaryotes. Trends Microbiol. 13:111-118.

Bateman, D. F., and Beer, S. V. 1965. Simultaneous production and synergistic action of oxalic acid and polygalacturonase during pathogenesis by Sclerotium rolfsii. Phytopathology 55:204-211.

Berg, G., and Hallmann, J. 2006. Pages 53-69 in: Control of Plant Pathogenic Fungi with Bacillus Endophytes. Springer, Berlin, Heidelberg.

Bloomfield, B. J., and Alexander, M. 1967. Melanins and resistance of fungi to lysis. J. Bacteriol. 93:1276.

Boland, G. J., and Hall, R. 1987. Epidemiology of white mold of white bean in Ontario. Can. J. Plant Pathol. 9:218-224.

Boland, G. J., and Hall, R. 1994. Index of plant hosts of Sclerotinia sclerotiorum. Can. J. Plant Pathol. 16:93-108.

Bolton, M. D., Thomma, B. P., and Nelson, B. D. 2006. Sclerotinia sclerotiorum (Lib.) de Bary: Biology and molecular traits of a cosmopolitan pathogen. Mol. Plant Pathol. 7:1-16.

De Clerck, E., Vanhoutte, T., Hebb, T., Geerinck, J., Devos, J., and De Vos, P. 2004. Isolation, characterization, and identification of bacterial contaminants in semifinal gelatin extracts. Appl. Environ. Microbiol. 70: 3664-3672.

Dimock, M. B., Kennedy, G. G., and Williams, W. G. 1982. Toxicity studies of analogs of 2-tridecanone, a naturally occurring toxicant from a wild tomato. J. Chem. Ecol. 8:837-842.

Djamei, A., Schipper, K., Rabe, F., Ghosh, A., Vincon, V., Kahnt, J., Osorio, S., Tohge, T., Fernie, A. R., and Feussner, I. 2011. Metabolic priming by a secreted fungal effector. Nature 478:395-398. 
Duncan, R. W. 2003. Evaluation of host tolerance, biological, chemical, and cultural control of Sclerotinia sclerotiorum in sunflower (Helianthus annuиs L.). M.S. thesis, University of Manitoba, Winnipeg, Manitoba, Canada.

Ellil, A. H. A. A. 1999. Sclerotial development, melanin production and lipid peroxidation by Sclerotium rolfsii. Folia Microbiol. (Praha) 44:181-186.

Fernando, W. G. D., Ramarathnam, R., Krishnamoorthy, A. S., and Savchuk, S. C. 2005. Identification and use of potential bacterial organic antifungal volatiles in biocontrol. Soil Biol. Biochem. 37:955-964.

Fialho, M., Carvalho, G., Martins, P. F., Azevedo, R. A., and Pascholati, S. F. 2014. Antioxidative response of the fungal plant pathogen Guignardia citricarpa to antimicrobial volatile organic compounds. Afr. J. Microbiol. Res. 8:2077-2084.

Finkel, T., and Holbrook, N. J. 2000. Oxidants, oxidative stress and the biology of ageing. Nature 408:239-247.

Fitter, A. H., and Garbaye, J. 1994. Interactions between mycorrhizal fungi and other soil organisms. Plant Soil 159:123-132.

Giorgio, A., Stradis, A. D., Cantore, P. L., and Iacobellis, N. S. 2015. Biocide effects of volatile organic compounds produced by potential biocontrol rhizobacteria on Sclerotinia sclerotiorum. Front. Microbiol. 6:1056.

Gong, A. D., Li, H. P., Yuan, Q. S., Song, X. S., Yao, W., He, W. J., Zhang, J. B., and Liao, Y. C. 2015. Antagonistic mechanism of iturin A and plipastatin A from Bacillus amyloliquefaciens S76-3 from wheat spikes against Fusarium graminearum. PLoS One 10:e116871.

Gu, Q., Y. Yang, Q. Yuan, G. Shi, L. Wu, Z. Lou, R. Huo, H. Wu, R. Borriss, and X. Gao. 2017. Bacillomycin D produced by Bacillus amyloliquefaciens is involved in the antagonistic interaction with the plant pathogenic fungus Fusarium graminearum. Appl. Environ. Microbiol. 83:e01075-17.

Heller, J., and Tudzynski, P. 2011. Reactive oxygen species in phytopathogenic fungi: Signaling, development, and disease. Annu. Rev. Phytopathol. 49: 369-390.

Huang, C. J., Tsay, J. F., Chang, S. Y., Yang, H. P., Wu, W. S., and Chen, C. Y. 2012. Dimethyl disulfide is an induced systemic resistance elicitor produced by Bacillus cereus C1L. Pest Manage. Sci. 68:1306-1310.

Kabbage, M., Williams, B., and Dickman, M. B. 2013. Cell Death Control: The Interplay of Apoptosis and Autophagy in the Pathogenicity of Sclerotinia sclerotiorum. PLoS Pathog. 9:e1003287.

Kai, M., Haustein, M., Molina, F., Petri, A., Scholz, B., and Piechulla, B. 2009. Bacterial volatiles and their action potential. Appl. Microbiol. Biotechnol. $81: 1001-1012$

Kim, K. S., Min, J. Y., and Dickman, M. B. 2008. Oxalic acid is an elicitor of plant programmed cell death during Sclerotinia sclerotiorum disease development. Mol. Plant-Microbe Interact. 21:605-612.

Kim, Y. M., Farrah, S., and Baney, R. H. 2007. Structure-antimicrobial activity relationship for silanols, a new class of disinfectants, compared with alcohols and phenols. Int. J. Antimicrob. Agents 29:217-222.

Kreft, S., and Kreft, M. 2009. Quantification of dichromatism: A characteristic of color in transparent materials. J. Opt. Soc. Am. A Opt. Image Sci. Vis. 26:1576.

Kubo, I., Muroi, H., and Kubo, A. 1995. Structural functions of antimicrobial long-chain alcohols and phenols. Bioorg. Med. Chem. 3:873-880.

Li, Q., Ning, P., Zheng, L., Huang, J., Li, G., and Hsiang, T. 2010. Fumigant activity of volatiles of Streptomyces globisporus JK-1 against Penicillium italicum on Citrus microcarpa. Postharvest Biol. Technol. 58:157-165.

Liang, X., Liberti, D., Li, M., Kim, Y. T., Hutchens, A., Wilson, R., and Rollins, J. A. 2015. Oxaloacetate acetylhydrolase gene mutants of Sclerotinia sclerotiorum do not accumulate oxalic acid, but do produce limited lesions on host-plants. Mol. Plant Pathol. 16:559-571.

Ma, M., Sun, Y., and Sun, G. 2003. Antimicrobial cationic dyes: Part 1: Synthesis and characterization. Dyes Pigments 58:27-35.

Mackie, A. E., and Wheatley, R. E. 1999. Effects and incidence of volatile organic compound interactions between soil bacterial and fungal isolates. Soil Biol. Biochem. 31:375-385.

Marciano, P., Magro, P., and Favaron, F. 1989. Sclerotinia sclerotiorum growth and oxalic acid production on selected culture media. FEMS Microbiol. Lett. 61:57-59.

McCain, A. H. 1966. A volatile antibiotic produced by Streptomyces griseus. Phytopathology 56:150.

Minuto, A., Spadaro, D., Garibaldi, A., and Gullino, M. L. 2006. Control of soilborne pathogens of tomato using a commercial formulation of Streptomyces griseoviridis and solarization. Crop Prot. 25:468-475.

Mitchell, A. M., Strobel, G. A., Moore, E., Robison, R., and Sears, J. 2010. Volatile antimicrobials from Muscodor crispans, a novel endophytic fungus. Microbiology 156:270-277.

Ntalli, N., Ratajczak, M., Oplos, C., Menkissogluspiroudi, U., and Adamski, Z. 2016. Acetic acid, 2-undecanone, and (e)-2-decenal ultrastructural malformations on Meloidogyne incognita. J. Nematol. 48:248-260.
Ping, L., and Boland, W. 2004. Signals from the underground: Bacterial volatiles promote growth in Arabidopsis. Trends Plant Sci. 9:263-266.

Posada, F., and Vega, F. E. 2005. Establishment of the fungal entomopathogen Beauveria bassiana (Ascomycota: Hypocreales) as an endophyte in cocoa seedlings (Theobroma cacao). Mycologia 97:1195-1200.

Poussereau, N., Gente, S., Rascle, C., Billongrand, G., and Fèvre, M. 2001. aspS encoding an unusual aspartyl protease from Sclerotinia sclerotiorum is expressed during phytopathogenesis. FEMS Microbiol. Lett. 194:27-32.

Purdy, L. H. 1979. Sclerotinia sclerotiorum: History, diseases and symptomatology, host range, geographic distribution, and impact. Phytopathology 69:875-880.

Rijavec, T., Lapanje, A., Dermastia, M., and Rupnik, M. 2007. Isolation of bacterial endophytes from germinated maize kernels. Can. J. Microbiol. 53: 802-808.

Seifbarghi, S., Borhan, M. H., Wei, Y., Coutu, C., Robinson, S. J., and Hegedus, D. D. 2017. Changes in the Sclerotinia sclerotiorum transcriptome during infection of Brassica napus. BMC Genomics 18:266.

Stokes, N. R., Thomaides-Brears, H. B., Barker, S., Bennett, J. M., Berry, J., Collins, I., Czaplewski, L. G., Gamble, V., Lancett, P., Logan, A., Lunniss, C. J., Peasley, H., Pommier, S., Price, D., Smee, C., and Haydon, D. J. 2013. Biological evaluation of benzothiazole ethyl urea inhibitors of bacterial type II topoisomerases. Antimicrobial Agents \& Chemotherapy 57(12): 5977.

Sumayo, M., Hahm, M. S., and Ghim, S. Y. 2013. Determinants of plant growth-promoting Ochrobactrum lupini KUDC1013 involved in induction of systemic resistance against Pectobacterium carotovorum subsp. carotovorum in tobacco leaves. Plant Pathol. J. 29:174-181.

Tahir, H. A. S., Qin, G., Wu, H., Niu, Y., Rong, H., and Gao, X. 2017. Bacillus volatiles adversely affect the physiology and ultrastructure of Ralstonia solanacearum and induce systemic resistance in tobacco against Bacillus wilt. Sci. Rep. 7:40481.

Ueda, J., Yamamoto, S., and Kurosawa, N. 2013. Paenibacillus thermoaerophilus sp. nov., a moderately thermophilic bacterium isolated from compost. Int. J. Syst. Evol. Microbiol. 63:3330-3335.

Vespermann, A., Kai, M., and Piechulla, B. 2007. Rhizobacterial volatiles affect the growth of fungi and Arabidopsis thaliana. Appl. Environ. Microbiol. 73:5639-5641.

Voda, K., Boh, B., and Vrtačnik, M. 2004. A quantitative structure-antifungal activity relationship study of oxygenated aromatic essential oil compounds using data structuring and PLS regression analysis. J. Mol. Model. 10: 76-84.

Wan, M., Li, G., Zhang, J., Jiang, D., and Huang, H. C. 2008. Effect of volatile substances of Streptomyces platensis F-1 on control of plant fungal diseases. Biol. Control 46:552-559.

Williams, B., Kabbage, M., Kim, H. J., Britt, R., and Dickman, M. B. 2011. Tipping the balance: Sclerotinia sclerotiorum secreted oxalic acid suppresses host defenses by manipulating the host redox environment. PLoS Pathog. 7:e1002107

Wu, L., Wu, H., Chen, L., Xie, S., Zang, H., Borriss, R., and Gao, X. 2014a. Bacilysin from Bacillus amyloliquefaciens FZB42 has specific bactericidal activity against harmful algal bloom species. Appl. Environ. Microbiol. 80: 7512-7520.

Wu, Y., Yuan, J., Raza, W., Shen, Q., and Huang, Q. 2014b. Biocontrol traits and antagonistic potential of Bacillus amyloliquefaciens strain NJZJSB3 against Sclerotinia sclerotiorum, a causal agent of canola stem rot. J. Microbiol. Biotechnol. 24:1327-1336.

Xie, S., Zang, H., Wu, H., Uddin, R. F., and Gao, X. 2018. Antibacterial effects of volatiles produced by Bacillus strain D13 against Xanthomonas oryzae pv. oryzae. Mol. Plant Pathol. 19:49-58.

Yuan, J., Ruan, Y., Wang, B., Zhang, J., Waseem, R., Huang, Q., and Shen, Q. 2013. Plant growth-promoting rhizobacteria strain Bacillus amyloliquefaciens NJN-6-enriched bio-organic fertilizer suppressed Fusarium wilt and promoted the growth of banana plants. J. Agric. Food Chem. 61: 3774-3780.

Zamioudis, C., Korteland, J., Van Pelt, J. A., Hamersveld, M., Dombrowski, N., Bai, Y., Hanson, J., Van Verk, M. C., Ling, H. Q., and Schulze-Lefert, P. 2015. Rhizobacterial volatiles and photosynthesis-related signals coordinate MYB72 expression in Arabidopsis roots during onset of induced systemic resistance and iron-deficiency responses. Plant J. 84:309-322.

Zhao, Y., Selvaraj, J. N., Xing, F., Zhou, L., Wang, Y., Song, H., Tan, X., Sun, L., Sangare, L., and Folly, Y. M. E. 2014. Antagonistic Action of Bacillus subtilis Strain SG6 on Fusarium graminearum. PLoS One 9:e92486.

Zhu, W., Wei, W., Fu, Y., Cheng, J., Xie, J., Li, G., Yi, X., Kang, Z., Dickman, M. B., and Jiang, D. 2013. A Secretory Protein of Necrotrophic Fungus Sclerotinia sclerotiorum That Suppresses Host Resistance. PLoS One 8: e53901. 